\title{
RELIABLE ITERATIVE METHODS FOR SOLVING 1D, 2D AND 3D FISHER'S EQUATION
}

\author{
Othman Mahdi Salih, MaJeed AhMed. AL-JaWary \\ Department of Mathematics, College of Education for Pure Science Ibn Al-Haitham, \\ University of Baghdad, Baghdad, Iraq.
}

*Corresponding author: majeed.a.w@ihcoedu.uobaghdad.edu.iq

(Received: 23rd March 2020; Accepted: $7^{\text {th }}$ October 2020; Published on-line: $4^{\text {th }}$ January 2021)

\begin{abstract}
In the present paper, three reliable iterative methods are given and implemented to solve the 1D, 2D and 3D Fisher's equation. Daftardar-Jafari method (DJM), Temimi-Ansari method (TAM) and Banach contraction method (BCM) are applied to get the exact and numerical solutions for Fisher's equations. The reliable iterative methods are characterized by many advantages, such as being free of derivatives, overcoming the difficulty arising when calculating the Adomian polynomial boundaries to deal with nonlinear terms in the Adomian decomposition method (ADM), does not request to calculate Lagrange multiplier as in the Variational iteration method (VIM) and there is no need to create a homotopy like in the Homotopy perturbation method (HPM), or any assumptions to deal with the nonlinear term. The obtained solutions are in recursive sequence forms which can be used to achieve the closed or approximate form of the solutions. Also, the fixed point theorem was presented to assess the convergence of the proposed methods. Several examples of 1D, 2D and 3D problems are solved either analytically or numerically, where the efficiency of the numerical solution has been verified by evaluating the absolute error and the maximum error remainder $(M E R)$ to show the accuracy and efficiency of the proposed methods. The results reveal that the proposed iterative methods are effective, reliable, time saver and applicable for solving the problems and can be proposed to solve other nonlinear problems. All the iterative process in this work implemented in MATHEMATICA ${ }^{\circledR} 12$.
\end{abstract}

ABSTRAK: Kajian ini berkenaan tiga kaedah berulang boleh percaya diberikan dan dilaksanakan bagi menyelesaikan 1D, 2D dan 3D persamaan Fisher. Kaedah DaftardarJafari (DJM), kaedah Temimi-Ansari (TAM) dan kaedah pengecutan Banach (BCM) digunakan bagi mendapatkan penyelesaian numerik dan tepat bagi persamaan Fisher. Kaedah berulang boleh percaya di kategorikan dengan pelbagai faedah, seperti bebas daripada terbitan, mengatasi masalah-masalah yang timbul apabila sempadan polinomial bagi mengurus kata tak linear dalam kaedah penguraian Adomian (ADM), tidak memerlukan kiraan pekali Lagrange sebagai kaedah berulang Variasi (VIM) dan tidak perlu bagi membuat homotopi sebagaimana dalam kaedah gangguan Homotopi (HPM), atau mana-mana anggapan bagi mengurus kata tak linear. Penyelesaian yang didapati dalam bentuk urutan berulang di mana ianya boleh digunakan bagi mencapai penyelesaian tepat atau hampiran. Juga, teorem titik tetap dibentangkan bagi menaksir kaedah bentuk hampiran. Pelbagai contoh seperti masalah 1D, 2D dan 3D diselesaikan samada secara analitik atau numerik, di mana kecekapan penyelesaian numerik telah ditentu sahkan dengan menilai ralat mutlak dan baki ralat maksimum (MER) bagi menentukan ketepatan dan kecekapan kaedah yang dicadangkan. Dapatan kajian menunjukkan kaedah berulang yang dicadangkan adalah berkesan, boleh percaya, jimat masa dan boleh guna bagi menyelesaikan masalah dan boleh dicadangkan menyelesaikan masalah tak linear lain. Semua proses berulang dalam kerja ini menggunakan MATHEMATICA ${ }^{\circledR} 12$. 
KEYWORDS: Fisher's equation, Iterative methods, Exact solution, Numerical solutions and Maximum error remainder.

\section{INTRODUCTION}

Many problems arising in engineering, science, finance, ecology, chemistry, etc., can be expressed by partial non-linear differential equations (PDEs). A non-linear PDE solution is a challenge for engineers and scientists where an analytical solution cannot be obtained. Therefore, many mathematicians have attempted to solve these problems in different ways and algorithms, for examples, ADM, VIM, HPM, homotopy analysis method (HAM), finite difference methods and some other approximate and numerical methods, see [1-6].

Fisher's equation is defined as the nonlinear reaction diffusion equation that describes the relationship between the diffusion and nonlinear multiplication of a species [7]. Fisher's equation is used in chemical kinetics and population dynamics which included problems such as nonlinear evolution of a population in a one-dimensional habitat and neutron population in a nuclear reaction and branching, the same equation occurs in neurophysiology, logistic growth models [8,9]. During the past half century, Fischer's equation was studied and a solution was found it, and the research field is still active to develop some good numerical algorithms and methods to obtain an accurate or approximate solution to it [10].

Moreover, some analytical, approximate and numerical methods were used and implemented to solve the Fisher's equation such as, finite elements and the Galerkin method [11], homotopy perturbation method [12], modified variational iteration method [13], Sinc collocation method [14]. In addition, Wazwaz and Gorguis studied the Fisher equation by using ADM [15]. In 2017, Parand and Nicarea solved Fischer's equation by using a spectral collocation method based on the Bessel functions of the first kind the Jacobian free Newtongeneralized minimum residual method with adaptive preconditions[16].

In this paper, the three iterative methods DJM, TAM and BCM will be applied to solve the 1D, 2D and 3D Fisher's equations to obtain either exact or numerical solutions. The first method is the DJM suggested by Daftardar-Gejji and Jafari in 2006 [17], the second method is the TAM proposed by Temimi and Ansari in 2011 [18] and the third method is the BCM introduced by Daftardar-Gejji and Bhalekar in 2009 [19].Theseiterative methods have been effectively used to solve different types of non-linear differential equations, for more details see $[20-26]$.

This paper has been arranged as follows: In section 2, the 1D, 2D and 3D Fisher's equation mathematical formulation will be given. The basic ideas of three semi-analytical iterative methods will be presented in section 3 . The convergence of the suggested techniques will be illustrated in section 4. In section 5, solving some examples of 1D, 2D and 3DFisher's equation by using the DJM, TAM and BCM will be given. Finally, the conclusion is given in section 6 . 


\section{THE MATHEMATICAL FORMULATION OF 1D, 2D AND 3D FISHER'S EQUATION}

Fisher's equation is nonlinear partial differential equation that belongs to the class of reaction diffusion equations and has many important applications in biology, chemistry, physics and medicine as is the case in many reactions spread equations $[13,16]$.

In this study, the 1D Fisher's equation can be simply present in following form

$$
w_{t}(x, t)=\alpha w_{x x}(x, t)+\beta R(w(x, t))+u(x, t), \quad 0 \leq t \leq T, \quad \mathrm{a} \leq x \leq b,
$$

with the following initial conditions:

$$
w(x, 0)=w_{0} .
$$

The 2D Fisher's equation is presented in this form

$$
\begin{aligned}
& w_{t}(x, y, t)=\alpha\left[w_{x x}(x, y, t)+w_{y y}(x, y, t)\right]+\beta R(w(x, y, t))+u(x, y, t), \\
& 0 \leq t \leq T, \quad \mathrm{a} \leq x, y \leq b,
\end{aligned}
$$

with the following initial conditions:

$$
w(x, y, 0)=w_{0} .
$$

The 3D Fisher's equation can be expressed in this form

$$
\begin{aligned}
& w_{t}(x, y, z, t) \\
& =\alpha\left[w_{x x}(x, y, z, t)+w_{y y}(x, y, z, t)+w_{z z}(x, y, z, t)\right]+\beta R(w(x, y, z, t)) \\
& +u(x, y, z, t), \\
& 0 \leq t \leq T, \quad a \leq x, y, z \leq b,
\end{aligned}
$$

with the following initial conditions:

$$
w(x, y, z, 0)=w_{0},
$$

where $t$ is the time, $x, y, z$ are the spatial coordinate, $\alpha$ the constant diffusion coefficient, $\beta$ the reaction factor and $R$ the nonlinear reaction term, $w$ unknown function and $u$ is known function represent the non- homogenous term.

\section{THE BASIC CONCEPTS OF THE THREE ITERATIVE METHODS}

In this section, the basic idea of the suggested three iterative methods DJM, TAM and $\mathrm{BCM}$ will be introduced.

\subsection{The basic steps of DJM}

Daftardar-Gejji and Jafari have considered the following nonlinear functional equation $[17,27]$ :

$$
w=g+L(w)+N(w),
$$

where $L$ and $N$ represent are linear and nonlinear operators, respectively, $g$ is a known function and $w$ is an unknown function.

We are looking for a solution wofEq. (4) and can be obtained by the following series:

$w=\sum_{p=0}^{\infty} w_{p}$. 
Because $L$ is linear operator, then

$L\left(\sum_{p=0}^{\infty} w_{p}\right)=\sum_{p=0}^{\infty} L\left(w_{p}\right)$.

Hence, Eq. (4) can be written as

$\sum_{p=0}^{\infty} w_{p}=g+\sum_{p=0}^{\infty} L\left(w_{p}\right)+N\left(\sum_{p=0}^{\infty} w_{p}\right)$,

and the $N$ can be decomposed as bellow

$N\left(\sum_{p=0}^{\infty} w_{p}\right)=N\left(w_{0}\right)+\sum_{i=1}^{\infty}\left\{N\left(\sum_{p=0}^{i} w_{p}\right)-N\left(\sum_{p=0}^{i-1} w_{p}\right)\right\}$.

Now, let us define the relation as below

$J_{0}=N\left(w_{0}\right)$,

$J_{1}=N\left(w_{0}+w_{1}\right)-N\left(w_{0}\right)$,

$J_{2}=N\left(w_{0}+w_{1}+w_{2}\right)-N\left(w_{0}+w_{1}\right)$,

$J_{i}=\left\{N\left(\sum_{p=0}^{i} w_{p}\right)-N\left(\sum_{p=0}^{i-1} w_{p}\right)\right\}, \quad i \geq 1$.

From the above relation we get

$N\left(\sum_{p=0}^{\infty} w_{p}\right)=J_{0}+J_{1}+J_{2}+\cdots+J_{i}+\cdots$

Now, we will define the inverse operator as follows

$$
L^{-1}(\cdot)=\int_{0}^{t}(\cdot) d \tau
$$

By taking the inverse for together sides of Eq. (4), and applying the initial condition, we obtain

$\sum_{p=0}^{\infty} w_{p}=f+L^{-1}\left(N\left(\sum_{p=0}^{\infty} w_{p}\right)\right)$

where $f$ represents the final formula for $L^{-1}(g)$.

Therefore, the components of the solution $w$ are

$w_{0}=f$,

$w_{1}=L^{-1}\left(J_{0}\right)$,

$w_{2}=L^{-1}\left(J_{1}\right)$, 
$w_{p+1}=L^{-1}\left(J_{p}\right), \quad p=0,1,2, \ldots$

As a result, the n-term approximate solution of Eq. (4) is presented by the following form

$$
\theta_{n}=\sum_{i=0}^{n} w_{i} .
$$

Finally, the solution $w$ for the nonlinear problem is given by

$$
w=\sum_{p=0}^{\infty} w_{p} .
$$

\subsection{The basic steps of TAM}

Temimi and Ansari have presented an iterative method namely (TAM) for solving nonlinear differential equations $[18,28]$.

To explain the basic ideas of the suggested technique, we assume the general form of partial differential equation

$$
L(w)+N(w)+g=0,
$$

with boundary condition, $B\left(w, \frac{\partial w}{\partial x}\right)=0$.

where $L$ is a linear operator, $N$ is a nonlinear operator, $x, t$ denotes the independent variables, $w$ is an unknown function, $g$ is a known function and $B$ is a boundary operator.

Now, we start by supposing that $w_{0}$ is an initial approximation of the problem $w$ through solving the following initial equation

$$
L\left(w_{0}\right)+g=0 \text {, with } B\left(w_{0}, \frac{\partial w_{0}}{\partial x}\right)=0 .
$$

To obtain the next iteration $w_{1}$ to the solution $w$, we must solve the following equation

$$
L\left(w_{1}\right)+g+N\left(w_{0}\right)=0 \text {, with } B\left(w_{1}, \frac{\partial w_{1}}{\partial x}\right)=0 .
$$

Similarly, all iterations $w_{n+1}$ can be obtained as

$$
L\left(w_{n+1}\right)+g+N\left(w_{n}\right)=0 \text {, with } B\left(w_{n+1}, \frac{\partial w_{n+1}}{\partial x}\right)=0 .
$$

Note that each of them $w_{n}$ is a solution to Eq. (9). Also, by increasing the iterations, we will obtain better accuracy for the approximate solution.

So, the solution for the Eq. (9) is given by

$$
w=\lim _{n \rightarrow \infty} w_{n} .
$$

\subsection{The basic steps of BCM}

To study the basic concept of the suggested technique, we assume the general form of nonlinear functional equation, see [19]:

$$
w=g+N(w),
$$

Now, we will define successive approximations as follows

$w_{0}=g$, 


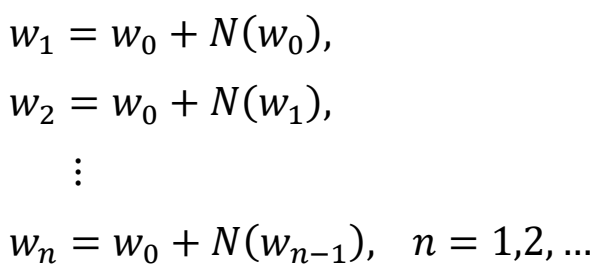

It has been shown that the series defined by Eq. (13) is convergent [19]. Thus, the solution of Eq. (12) is given by

$w=\lim _{n \rightarrow \infty} w_{n}$.

\section{THE CONVERGENCE OF THE PROPOSED TECHNIQUES}

To show the convergence of the DJM, TAM and BCM, we are going to discuss the basic concepts and the fundamental theorems. In the DJM the convergence can be directly proved. However, in TAM and BCM, we should follow some steps as below

$$
\begin{aligned}
& v_{0}=w_{0}, \\
& v_{1}=A\left[v_{0}\right], \\
& v_{2}=A\left[v_{0}+v_{1}\right], \\
& \quad \vdots \\
& v_{n+1}=A\left[v_{0}+v_{1}+\cdots+v_{n}\right] .
\end{aligned}
$$

where the operator $A$ can be defined by the following form

$$
A\left[v_{p}\right]=S_{p}-\sum_{i=0}^{p-1} v_{i}, \quad p=1,2,3, \ldots
$$

where the term $S_{p}$ is the solution appeared from the iterative methods.

Now, for the TAM as

$$
L\left(v_{p}\right)+g+N\left(\sum_{i=0}^{p-1} v_{i}\right)=0, p=1,2,3, \ldots
$$

For the BCM

$$
v_{p}=v_{0}+N\left(\sum_{i=0}^{p-1} v_{i}\right), \quad p=1,2,3, \ldots
$$

Now, applying the same conditions that used in the iterative technique, we have

$$
w=\lim _{n \rightarrow \infty} w_{n}=\sum_{n=0}^{\infty} v_{n}
$$

Hence, by using the Eqs. (15) and (16), we can get the solution by the following form

$$
w=\sum_{i=0}^{\infty} v_{i}
$$

The following theorems show the convergence of the proposed methods: the DJM, BCM and TAM, more details for the theorems can be found in [29]. 
Theorem 4.1. Let $A$ presented in Eq. (16), be an operator from a Hilbert spaceH to $H$. The series solution $w_{n}=\sum_{i=0}^{n} v_{i}$ is convergent if $\exists 0<\lambda<1$ when $\left\|A\left[v_{0}+v_{1}+\cdots+v_{i+1}\right]\right\| \leq$ $\lambda\left\|A\left[v_{0}+v_{1}+\cdots+v_{i}\right]\right\|$ (such that $\left.\left\|v_{i+1}\right\| \leq \lambda\left\|v_{i}\right\|\right) \forall \mathrm{i}=0,1, \ldots$

Theorem 4.1 is a specific case from the Banach's fixed point theorem which is a sufficient condition to study the convergence of the proposed iterative methods.

Theorem 4.2. If the series solution $w=\sum_{i=0}^{\infty} v_{i}$ convergent, then this series will consider the exact solution of the present nonlinear problem.

Theorems 4.1 and 4.2 show that the achieved solution from the DJM, TAM and BCM that is given in Eqs. (6), (10) and (13), respectively, for the nonlinear equation (Eq. (4)) is convergent to the exact solution under the given condition, $\exists 0<\lambda<1$; $\left\|v_{i+1}\right\| \leq$ $\lambda\left\|v_{i}\right\| \forall i=0,1,2, \ldots$.

In other words, we will define the following parameter as

$$
\delta_{i}=\left\{\begin{array}{lll}
\frac{\left\|v_{i+1}\right\|}{\left\|v_{i}\right\|} & \text { if } & \left\|v_{i}\right\| \neq 0 \\
0 & \text { if } & \left\|v_{i}\right\|=0
\end{array}\right.
$$

Then, the series solution $\sum_{i=0}^{\infty} v_{i}$ for the nonlinear problem converges to the exact solution $w$, when $0 \leq \delta_{i}<1, \forall i=0,1,2, \ldots$..Moreover, the maximum truncation error can be calculated using the following form: $\left\|w-\sum_{i=0}^{n} v_{i}\right\| \leq \frac{1}{1-\delta} \delta^{n+1}\left\|v_{0}\right\|$, where $\delta=\max \left\{\delta_{i}, i=0,1, \ldots, n\right\}$ as shown in theorem 4.3 .

\section{SOLVING THE 1D, 2D AND 3D FISHER'S EQUATION}

In this section we are going to solve some examples of the 1D, 2D and 3D Fisher's equations by using the DJM, TAM and BCM.

Example 5.1. Consider the 1D Fisher's equation given in Eq. (1), when we substitute the values of $\alpha=\beta=1$, as follows[12, 13]:

$$
w_{t}=w_{x x}+w(1-w) \text {, }
$$

The constant initial condition is given as, $w(x, 0)=\lambda$.

\section{Solving example 5.1 by using the DJM}

First of all, to implement the DJM for the 1D Fisher's equation, we write the operator form of the Eq. (20) as follows

$$
L_{t}(w)=N(w),
$$

where $L_{t}=\frac{\partial}{\partial t}$ and $N(w)=w_{x x}+w(1-w)$, is the nonlinear operator for the 1D Fisher's equation.

By taking the inverse for together sides of Eq. (21) and applying the initial condition, we obtain

$$
w=\lambda+L_{t}^{-1} N(w) .
$$

Finally, according to the DJM for Eq. (22) and by applying the recurrence relation, we achieve the components $w_{n}$ as the following in a series form

$w_{0}=\lambda$,

$w_{1}=L_{t}^{-1}\left(J_{0}\right)=L_{t}^{-1} N\left(w_{0}\right)=t \lambda-t \lambda^{2}$, 


$$
\begin{aligned}
w_{2} & =L_{t}^{-1}\left(J_{1}\right)=L_{t}^{-1} N\left(w_{0}+w_{1}\right)-w_{1}, \\
& =\frac{t^{2} \lambda}{2}-\frac{3 t^{2} \lambda^{2}}{2}-\frac{t^{3} \lambda^{2}}{3}+t^{2} \lambda^{3}+\frac{2 t^{3} \lambda^{3}}{3}-\frac{t^{3} \lambda^{4}}{3},
\end{aligned}
$$

$\vdots$

Moreover, by using a similar way the iterations $w_{3}$ and $w_{4}$ were also calculated but for brevity is not mentioned here.

Thus, we get the following approximate solutions

$$
\begin{aligned}
& \theta_{1}=w_{0}+w_{1}=\lambda+\left(\lambda-\lambda^{2}\right) t+O[t]^{5}, \\
& \theta_{2}=w_{0}+w_{1}+w_{2}=\lambda+\left(\lambda-\lambda^{2}\right) t+\left(\frac{\lambda}{2}-\frac{3 \lambda^{2}}{2}+\lambda^{3}\right) t^{2}+\frac{1}{3}\left(-\lambda^{2}+2 \lambda^{3}-\lambda^{4}\right) t^{3}+O[t]^{5}, \\
& \quad \vdots
\end{aligned}
$$

In general, according to Eq. (7) the $n$-term approximate solution obtained by the DJM will be

$$
\theta_{n}=\sum_{i=0}^{n} w_{i}=w_{0}+w_{1}+w_{2}+w_{3}+w_{4}+\cdots
$$

Hence, according to the Eq. (8), we obtain the exact solution of Eq. (20) in a series form by sum of the above components $w_{i}$ obtained from the DJM, this has the closed form obtained upon using the Taylor expansion:

$$
w=\sum_{p=0}^{\infty} w_{p}=\frac{\lambda e^{t}}{1-\lambda+\lambda e^{t}} .
$$

\section{Solving example 5.1 by using the TAM}

To implement the TAM for the 1D Fisher's equation, we re-write the Eq. (20) in the operator form, as follows

$$
L(w)=w_{t}, \quad N(w)=w_{x x}+w(1-w),
$$

with initial condition, $w(x, 0)=\lambda$.

We start by supposing that $w_{0}$ is an initial approximation of the problem $w$ through solving the following initial equation

$$
L_{t}\left(w_{0}\right)=0 \text {, with } w_{0}(x, 0)=\lambda, L_{t}=\frac{\partial}{\partial t} .
$$

Then, we get

$$
w_{0}=\lambda \text {. }
$$

Also, to get the next iteration, we have to solve the following problem

$$
L_{t}\left(w_{1}\right)+N\left(w_{0}\right)=0 \text {, with } w_{1}(x, 0)=\lambda \text {. }
$$

Then, we get

$$
w_{1}=\lambda+\left(\lambda-\lambda^{2}\right) t+O[t]^{5} .
$$

In the second iteration, we have to solve the following problem

$$
L_{t}\left(w_{2}\right)+N\left(w_{1}\right)=0 \text {, with } w_{2}(x, 0)=\lambda \text {. }
$$

Thus, we get 


$$
w_{2}=\lambda+\left(\lambda-\lambda^{2}\right) t+\left(\frac{\lambda}{2}-\frac{3 \lambda^{2}}{2}+\lambda^{3}\right) t^{2}+\frac{1}{3}\left(-\lambda^{2}+2 \lambda^{3}-\lambda^{4}\right) t^{3}+O[t]^{5} .
$$

Furthermore, by proceeding in this way the iterations $w_{3}$ and $w_{4}$ were also calculated but for the purpose of brevity is not mentioned here.Then, each iteration of the $w_{i}$ represents an approximate solution to the Eq. (20).

Thus, According to Eq. (11) we obtain the exact solution upon using the Taylor expansion:

$$
w=\lim _{n \rightarrow \infty} w_{n}=\frac{\lambda e^{t}}{1-\lambda+\lambda e^{t}} .
$$

\section{Solving example 5.1 by using the BCM}

To implement the BCM to solve the Eq. (20), by following the identical steps as used in the DJM, we obtain Eq. (22).

Also, suppose

$$
g=\lambda \text { and } N(w)=L_{t}^{-1} N(w),
$$

where, $L_{t}^{-1}(\cdot)=\int_{0}^{t}(\cdot) d t, N(w)=w_{x x}+w(1-w)$.

Applying the steps of the BCM, we get

$$
\begin{aligned}
& w_{0}=g=\lambda, \\
& w_{n}=w_{0}+N\left(w_{n-1}\right), n \in \mathbb{N} .
\end{aligned}
$$

Hence,

$$
\begin{aligned}
& w_{1}=\lambda+\left(\lambda-\lambda^{2}\right) t+O[t]^{5} \\
& w_{2}=\lambda+\left(\lambda-\lambda^{2}\right) t+\left(\frac{\lambda}{2}-\frac{3 \lambda^{2}}{2}+\lambda^{3}\right) t^{2}+\frac{1}{3}\left(-\lambda^{2}+2 \lambda^{3}-\lambda^{4}\right) t^{3}+O[t]^{5}, \\
& \vdots
\end{aligned}
$$

Moreover, by using a similar way the iterations $w_{3}$ and $w_{4}$ were also calculated but for brevity is not mentioned here.

Also, each iteration of the $w_{i}$ represents an approximate solution to the Eq. (20) and so the exact solution obtained by the BCM will be the similar to exact solution obtained by the DJM and TAM.

Example 5.2. Consider the 1D Fisher's equation given in Eq. (1) as follows [30, 31]:

$$
w_{t}=\alpha w_{x x}+\beta w(1-w),
$$

The initial condition is given as, $w(x, 0)=\lambda \operatorname{Sech}[10 x]^{2}$. The exact solution is unknown.

\section{Solving example 5.2 by using the DJM}

To implement the DJM to solve Eq.(24), we write it in the operator form, as follows

$$
L_{t}(w(x, t))=N(w),
$$

where, $L_{t}=\frac{\partial}{\partial t}$ and $N(w)=\alpha w_{x x}+\beta w(1-w)$, is the nonlinear operator of Eq.(24).

By taking the inverse for together sides of Eq. (25) and applying the initial condition, we obtain

$$
w=\lambda \operatorname{Sech}[10 x]^{2}+L_{t}^{-1} N(w) .
$$


Finally, according to the DJM for Eq. (26) and by applying the recurrence relation, we achieve the components $w_{n}$ as the following in a series form

$w_{0}=\lambda \operatorname{Sech}[10 x]^{2}$,

$w_{1}=L_{t}^{-1}\left(J_{0}\right)=L_{t}^{-1} N\left(w_{0}\right)=\frac{1}{2} \lambda(-800 \alpha+\beta-2 \beta \lambda+(400 \alpha+$

$\beta) \operatorname{Cosh}[20 x]) \operatorname{Sech}[10 x]^{4} t+O[t]^{3}$,

$w_{2}=L_{t}^{-1}\left(J_{1}\right)=L_{t}^{-1} N\left(w_{0}+w_{1}\right)-w_{1}$

$$
=\frac{1}{16} \lambda\left(5280000 \alpha^{2}+800 \alpha \beta(-3+20 \lambda)+\beta^{2}(3+4 \lambda(-3+4 \lambda))-4\left(1040000 \alpha^{2}+\right.\right.
$$

$\left.\left.\beta^{2}(-1+3 \lambda)+400 \alpha(\beta+6 \beta \lambda)\right) \operatorname{Cosh}[20 x]+(400 \alpha+\beta)^{2} \operatorname{Cosh}[40 x]\right) \operatorname{Sech}[10 x]^{6} t^{2}+$

$O[t]^{3}$,

$\vdots$

Also, the iterations $w_{3}$ and $w_{4}$ were calculated but for the purpose of brevity is not mentioned here.

In general, according to Eq. (7) the $n$-term approximate solution obtained by the DJM will be

$$
w_{i}=\sum_{i=0}^{4} w_{i}=w_{0}+w_{1}+w_{2}+w_{3}+w_{4} \text {. }
$$

To prove the convergence analysis for the DJM for the Eq. (24), we have applied the process as presented in section 4 . Hence, let choose the same above components obtained by the DJM, we get

$$
\begin{aligned}
& v_{0}=w_{0}=\lambda \operatorname{Sech}[10 x]^{2}, \\
& v_{1}=w_{1}=\frac{1}{2} \lambda(-800 \alpha+\beta-2 \beta \lambda+(400 \alpha+\beta) \operatorname{Cosh}[20 x]) \operatorname{Sech}[10 x]^{4} t+O[t]^{3}, \\
& \vdots
\end{aligned}
$$

and so on, when we substitute the values of $\alpha=0.1, \lambda=0.1$ and $\beta=1$ in the iterations above and we evaluate the $\delta_{i}$ given in Eq. (19) to check the convergent conditions of the obtained estimated solution, then, we get

$\delta_{0}=\frac{\left\|v_{1}\right\|}{\left\|v_{0}\right\|}=0.001875362147319159<1$,

$\delta_{1}=\frac{\left\|v_{2}\right\|}{\left\|v_{1}\right\|}=0.00407630739235568<1$,

$\delta_{2}=\frac{\left\|v_{3}\right\|}{\left\|v_{2}\right\|}=0.005390541847501205<1$,

$\delta_{3}=\frac{\left\|v_{4}\right\|}{\left\|v_{3}\right\|}=0.007399148330331557<1$.

The results of $\delta_{i}$, for all $i \geq 0,0<t<1$ and $0 \leq x \leq 1$, are less than one. Therefore, according to the convergence condition, the approximate solution obtained by the DJM is converges.

\section{Solving example 5.2 by using the TAM}

To implement the TAM for solving the Eq. (24), we write it in the operator form, so we have the following form

$$
L(w)=w_{t}, \quad N(w)=\alpha w_{x x}+\beta w(1-w),
$$


with initial condition, $w(x, 0)=\lambda \operatorname{Sech}[10 x]^{2}$.

We start by supposing that $w_{0}$ is an initial approximation of the problem $w$ through solving the following initial equation

$$
L_{t}\left(w_{0}\right)=0 \text {, with } w_{0}(x, 0)=\lambda \operatorname{Sech}[10 x]^{2}, L_{t}=\frac{\partial}{\partial t} .
$$

Then, we get

$$
w_{0}=\lambda \operatorname{Sech}[10 x]^{2} \text {, }
$$

Also, to obtain the next iteration, we have to solve the following problem

$$
L_{t}\left(w_{1}\right)+N\left(w_{0}\right)=0 \text {, with } w_{1}(x, 0)=\lambda \operatorname{Sech}[10 x]^{2} .
$$

Then, we get

$$
\begin{aligned}
& w_{1}=\lambda \operatorname{Sech}[10 x]^{2}+\frac{1}{2} \lambda(-800 \alpha+\beta-2 \beta \lambda+(400 \alpha+\beta) \operatorname{Cosh}[20 x]) \operatorname{Sech}[10 x]^{4} t+ \\
& O[t]^{3} .
\end{aligned}
$$

In the second iteration, we have to solve the following problem

$$
L_{t}\left(w_{2}\right)+N\left(w_{1}\right)=0 \text {, with } w_{2}(x, 0)=\lambda \operatorname{Sech}[10 x]^{2} .
$$

Thus, we get

$$
\begin{aligned}
& \quad w_{2}=\lambda \operatorname{Sech}[10 x]^{2}+\frac{1}{2} \lambda(-800 \alpha+\beta-2 \beta \lambda+(400 \alpha+\beta) \operatorname{Cosh}[20 x]) \operatorname{Sech}[10 x]^{4} t+ \\
& \frac{1}{16} \lambda\left(5280000 \alpha^{2}+800 \alpha \beta(-3+20 \lambda)+\beta^{2}(3+4 \lambda(-3+4 \lambda))-4\left(1040000 \alpha^{2}+\right.\right. \\
& \left.\left.\beta^{2}(-1+3 \lambda)+400 \alpha(\beta+6 \beta \lambda)\right) \operatorname{Cosh}[20 x]+(400 \alpha+\beta)^{2} \operatorname{Cosh}[40 x]\right) \operatorname{Sech}[10 x]^{6} t^{2}+ \\
& O[t]^{3},
\end{aligned}
$$

Also, the iterations $w_{3}$ and $w_{4}$ were calculated but for the purpose of brevity is not mentioned here.

To prove the convergence of the TAM for the Eq. (24), we have applied the procedure as presented in Eqs. (15), (16) and (17), and we evaluate the $\delta_{i}$ given in Eq. (19) to check the convergent conditions of the obtained estimated solution, then we get:

$\delta_{0}=\frac{\left\|v_{1}\right\|}{\left\|v_{0}\right\|}=0.0018753621473192403<1$,

$\delta_{1}=\frac{\left\|v_{2}\right\|}{\left\|v_{1}\right\|}=0.004076307392334906<1$,

$\delta_{2}=\frac{\left\|v_{3}\right\|}{\left\|v_{2}\right\|}=0.0053905418254422<1$,

$\delta_{3}=\frac{\left\|v_{4}\right\|}{\left\|v_{3}\right\|}=0.007399147822582866<1$.

The results of $\delta_{i}$, for all $i \geq 0,0<t<1$ and $0 \leq x \leq 1$, are less than one. Therefore, according to the convergence condition, the approximate solution obtained by the TAM is converges.

\section{Solving example 5.2 by using the BCM}

To implement the BCM to solve the Eq. (24), by following the identical steps as used in the DJM, we obtain Eq. (26).

Also, suppose, 


$$
g=\lambda \operatorname{Sech}[10 x]^{2} \text { and } N(w)=L_{t}^{-1} N(w),
$$

where, $L_{t}^{-1}(\cdot)=\int_{0}^{t}(\cdot) d t, N(w)=\alpha w_{x x}+\beta w(1-w)$.

Applying the steps of the BCM, we get

$$
\begin{aligned}
& w_{0}=g=\lambda \operatorname{Sech}[10 x]^{2}, \\
& w_{n}=w_{0}+N\left(w_{n-1}\right), n \in \mathbb{N} .
\end{aligned}
$$

Hence,

$$
\begin{gathered}
w_{1}=\lambda \operatorname{Sech}[10 x]^{2}+\frac{1}{2} \lambda(-800 \alpha+\beta-2 \beta \lambda+(400 \alpha+\beta) \operatorname{Cosh}[20 x]) \operatorname{Sech}[10 x]^{4} t \\
+O[t]^{3}, \\
\begin{aligned}
& w_{2}=\lambda \operatorname{Sech}[10 x]^{2}+\frac{1}{2} \lambda(-800 \alpha+\beta-2 \beta \lambda+(400 \alpha+\beta) \operatorname{Cosh}[20 x]) \operatorname{Sech}[10 x]^{4} t \\
&+ \frac{1}{16} \lambda\left(5280000 \alpha^{2}+800 \alpha \beta(-3+20 \lambda)+\beta^{2}(3+4 \lambda(-3+4 \lambda))\right. \\
&-4\left(1040000 \alpha^{2}+\beta^{2}(-1+3 \lambda)+400 \alpha(\beta+6 \beta \lambda)\right) \operatorname{Cosh}[20 x] \\
&\left.+(400 \alpha+\beta)^{2} \operatorname{Cosh}[40 x]\right) \operatorname{Sech}[10 x]^{6} t^{2}+O[t]^{3} .
\end{aligned}
\end{gathered}
$$

Also, the iterations $w_{3}$ and $w_{4}$ were calculated but for the purpose of brevity is not mentioned here.

To prove the convergence analysis for the BAM for the Eq. (24), we have applied the similar process as presented in section 4 and then, we evaluate the $\delta_{i}$ given in Eq. (19) to check the convergent conditions of the obtained estimated solution, then we get

$\delta_{0}=\frac{\left\|v_{1}\right\|}{\left\|v_{0}\right\|}=0.0018753621473191209<1$,

$\delta_{1}=\frac{\left\|v_{2}\right\|}{\left\|v_{1}\right\|}=0.004076307392346145<1$,

$\delta_{2}=\frac{\left\|v_{3}\right\|}{\left\|v_{2}\right\|}=0.005390541859136445<1$,

$\delta_{3}=\frac{\left\|v_{4}\right\|}{\left\|v_{3}\right\|}=0.0073991506075805555<1$.

The results of $\delta_{i}$, for all $i \geq 0,0<t<1$ and $0 \leq x \leq 1$, are less than one. Therefore, according to the convergence condition, the approximate solution obtained by the BCM is converges.

Because the exact solution of the Eq. (24) is unknown, the $M E R_{n}$ will be calculated as follows, $M E R_{n}=\max _{0 \leq x \leq 1}\left|w_{t}-\alpha w_{x x}-\beta w(1-w)\right|$, to test the efficiency of the approximate solutions that we obtained by the DJM, TAM, BCM, and compared them with the ADM and VIM $[13,31]$, for two values of the time $t$ equal to either 0.0001 or 0.001 . From Fig. 1, it can be easily recognized that the error is decreasing by increasing the number of iterations. Also, good agreement have been achieved with ADM and VIM, without required to calculate Adomian polynomials to handle the nonlinear terms in ADM, or compute Lagrange multiplier as in VIM and time saver. 


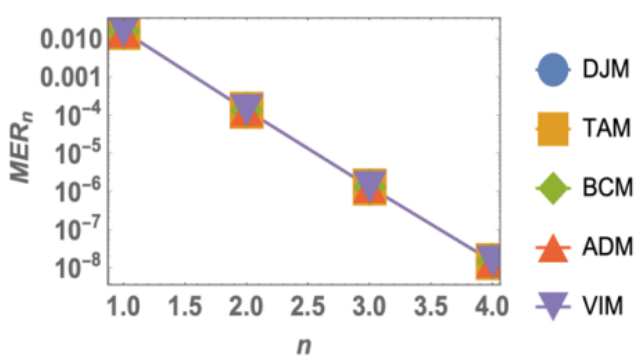

(a)

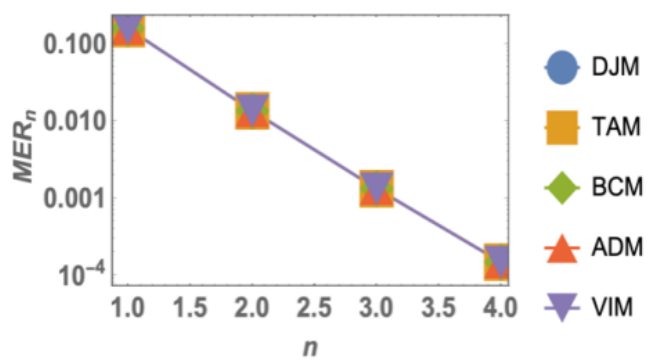

(b)

Fig. 1. The $M E R_{n}$ values for example 5.2 obtained by the DJM, TAM, BCM, ADM and VIM for times (a) $t=0.0001$, (b) $t=0.001$.

Example 5.3. Consider the 2D Fisher's equation given in Eq. (2), when we substitute the values of $\alpha=\beta=1$, as follows [11,16]:

$$
w_{t}=w_{x x}+w_{y y}+t w(1-w)+u(x, y, t),
$$

and the initial condition, $w(x, y, 0)=x^{2}+y^{2}$.

where, $u(x, y, t)=-4+2 t-t\left(1-t^{2}-x^{2}-y^{2}\right)\left(t^{2}+x^{2}+y^{2}\right), \quad 0<t<1$. The exact solution for this equation is

$w=x^{2}+y^{2}+t^{2}$.

\section{Solving example 5.3 by using the DJM}

To implement the DJM to solve Eq. (27), we write it in the operator form, as follows

$$
L_{t}(w)=N(w) \text {, }
$$

where, $L_{t}=\frac{\partial}{\partial t}$ and $N(w)=w_{x x}+w_{y y}+t w(1-w)+u(x, y, t)$, is the nonlinear operator for the Eq. (27).

By taking the inverse for both sides of Eq. (28), and applying the initial condition, we get

$$
w=\left(x^{2}+y^{2}\right)+L_{t}^{-1} N(w) .
$$

Finally, according to the DJM for Eq. (29) and by applying the recurrence relation, we achieve the components $w_{n}$ as the following in a series form

$$
\begin{aligned}
& w_{0}=x^{2}+y^{2}, \\
& w_{1}=L_{t}^{-1}\left(J_{0}\right)=L_{t}^{-1} N\left(w_{0}\right)=t^{2}-\frac{t^{4}}{4}+\frac{t^{6}}{6}+\frac{t^{4} x^{2}}{2}+\frac{t^{4} y^{2}}{2}, \\
& w_{2}=L_{t}^{-1}\left(J_{1}\right)=L_{t}^{-1} N\left(w_{0}+w_{1}\right)-w_{1}
\end{aligned}
$$




$$
\begin{aligned}
=\frac{t^{4}}{4} & +\frac{2 t^{5}}{5}-\frac{5 t^{6}}{24}+\frac{t^{8}}{12}-\frac{19 t^{10}}{480}+\frac{t^{12}}{144}-\frac{t^{14}}{504}-\frac{t^{4} x^{2}}{2}+\frac{t^{6} x^{2}}{6}-\frac{t^{8} x^{2}}{6}+\frac{t^{10} x^{2}}{40} \\
& -\frac{t^{12} x^{2}}{72}-\frac{t^{6} x^{4}}{6}-\frac{t^{10} x^{4}}{40}-\frac{t^{4} y^{2}}{2}+\frac{t^{6} y^{2}}{6}-\frac{t^{8} y^{2}}{6}+\frac{t^{10} y^{2}}{40}-\frac{t^{12} y^{2}}{72}-\frac{1}{3} t^{6} x^{2} y^{2} \\
& -\frac{1}{20} t^{10} x^{2} y^{2}-\frac{t^{6} y^{4}}{6}-\frac{t^{10} y^{4}}{40},
\end{aligned}
$$

$\vdots$

Furthermore, by proceeding in this way the iterations $w_{3}$ and $w_{4}$ were also calculated but for the purpose of brevity is not mentioned here.

To prove the convergence analysis of the DJM for the Eq. (27), we have applied the process as presented in section 4 . Hence, let choose the same above components obtained by the DJM, we get

$v_{0}=w_{0}=x^{2}+y^{2}$,

$v_{1}=w_{1}=t^{2}-\frac{t^{4}}{4}+\frac{t^{6}}{6}+\frac{t^{4} x^{2}}{2}+\frac{t^{4} y^{2}}{2}$,

$\vdots$

and so on, by using the iterations above and we evaluate the $\delta_{i}$ given in Eq. (19) to check the convergent conditions of the obtained approximate solution. Then, we get

$\delta_{0}=\frac{\left\|v_{1}\right\|}{\left\|v_{0}\right\|}=0.00005000375008333333<1$,

$\delta_{1}=\frac{\left\|v_{2}\right\|}{\left\|v_{1}\right\|}=0.00007459982180570717<1$,

$\delta_{2}=\frac{\left\|v_{3}\right\|}{\left\|v_{2}\right\|}=0.005312394687736893<1$,

$\delta_{3}=\frac{\left\|v_{4}\right\|}{\left\|v_{3}\right\|}=0.00021050502578039127<1$.

The results of $\delta_{i}$, for all $i \geq 0,0<t<1$ and $0 \leq x, y \leq 1$, are less than one. Therefore, the approximate solution obtained by the DJM is converges.

Also, the absolute error (Abs. errs.) will be calculated to check the accuracy of the approximate solutions that obtained by the DJM for three values of the time $t=$ $0.1,0.01$ and 0.001 , presented in Fig. 2. Moreover, Table 1 shows the absolute error values obtained by DJM for the iterations with $x=\{0,0.2,0.4,0.6,0.8,1\}$. It can be easily recognized that the error is decreasing by increasing the number of iterations and decreasing the time. 


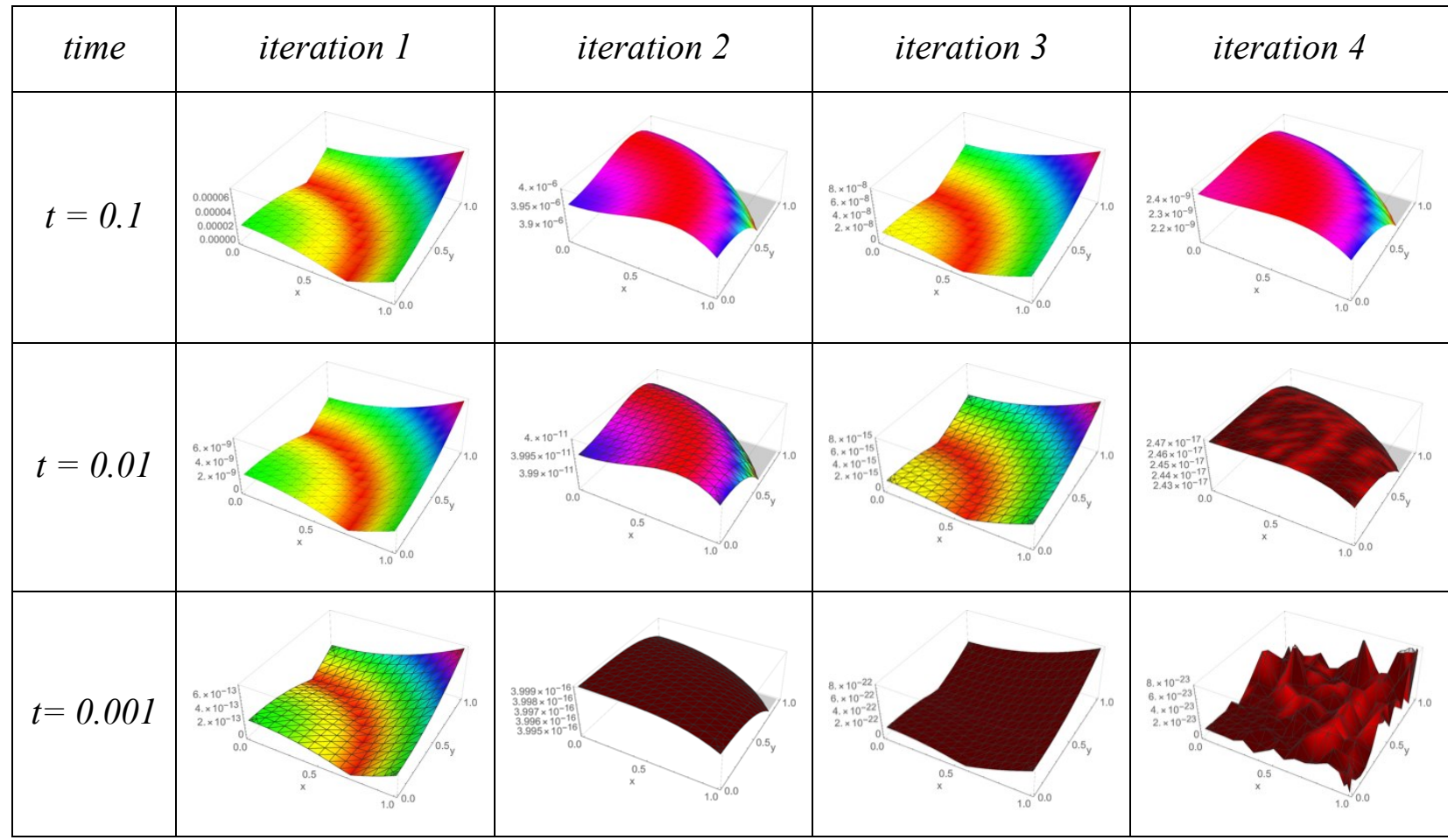

Fig. 2. The absolute error values for example 5.3 obtained by the DJM for $w_{1}, w_{2}, w_{3}$, and $w_{4}$ with different values of $t$.

Table 1: The absolute error values for example 5.3 obtained by DJM, for four iterations with different values of $t$.

\begin{tabular}{|c|c|c|c|c|c|}
\hline Time & $x_{i}$ & Abs. errs. For $1^{\text {st iteration }}$ & Abs. errs. For $2^{\text {nd }}$ iteration & Abs. errs. For $3^{\text {rditeration }}$ & Abs. errs. For $4^{\text {th }}$ iteration \\
\hline \multirow[t]{6}{*}{$t=0.1$} & $\mathbf{0}$ & 0.00002516666666677221 & 0.0000039574960347114 & $3.439519622754291 \times 10^{-8}$ & $2.367214207006091 \times 10^{-9}$ \\
\hline & 0.2 & 0.000027166666666776434 & 0.000003950495930156153 & $3.636235764046649 \times 10^{-8}$ & $2.352566504062037 \times 10^{-9}$ \\
\hline & 0.4 & 0.000033166666666789095 & 0.000003926295568490412 & $4.225011372322602 \times 10^{-8}$ & $2.303341876975943 \times 10^{-9}$ \\
\hline & 0.6 & 0.0000431666666668102 & 0.00000387529480571418 & $5.200767991296621 \times 10^{-8}$ & $2.203745339426222 \times 10^{-9}$ \\
\hline & 0.8 & 0.00005716666666683975 & 0.000003781493401827455 & $6.551841495654667 \times 10^{-8}$ & $2.027660150299521 \times 10^{-9}$ \\
\hline & 1 & 0.00007516666666687773 & 0.000003622491020830237 & $8.255182044155353 \times 10^{-8}$ & $1.739110699410879 \times 10^{-9}$ \\
\hline \multirow[t]{7}{*}{$t=0.01$} & $x_{i}$ & Abs. errs. For $1^{\text {stiteration }}$ & Abs. errs. For $2^{\text {nd }}$ iteration & Abs. errs. For $3^{\text {rditeration }}$ & Abs. errs. For $4^{\text {th }}$ iteration \\
\hline & $\mathbf{0}$ & $2.500166636275423 \times 10^{-9}$ & $3.995843050700178 \times 10^{-11}$ & $3.428213061620738 \times 10^{-15}$ & $2.459218564137952 \times 10^{-17}$ \\
\hline & 0.2 & $2.700166635059928 \times 10^{-9}$ & $3.995150072691333 \times 10^{-11}$ & $3.626173005459958 \times 10^{-15}$ & $2.45742245436945 \times 10^{-17}$ \\
\hline & 0.4 & $3.300166631413446 \times 10^{-9}$ & $3.992751138664317 \times 10^{-11}$ & $4.219916824177479 \times 10^{-15}$ & $2.451761901624386 \times 10^{-17}$ \\
\hline & 0.6 & $4.300166625335975 \times 10^{-9}$ & $3.987686248617691 \times 10^{-11}$ & $5.208940479372794 \times 10^{-15}$ & $2.441165215801239 \times 10^{-17}$ \\
\hline & 0.8 & $5.700166616827516 \times 10^{-9}$ & $3.978355402549054 \times 10^{-11}$ & $6.592083907044729 \times 10^{-15}$ & $2.421667439210999 \times 10^{-17}$ \\
\hline & 1 & $7.500166605888068 \times 10^{-9}$ & $3.962518600455048 \times 10^{-11}$ & $8.367051017590978 \times 10^{-15}$ & $2.391594246117009 \times 10^{-17}$ \\
\hline \multirow[t]{7}{*}{$t=0.001$} & $x_{i}$ & Abs. errs. For $1^{\text {st }}$ iteration & Abs. errs. For $2^{\text {nd }}$ iteration & Abs. errs. For $3^{\text {rd }}{ }^{\text {iteration }}$ & Abs. errs. For $4^{\text {th }}$ iteration \\
\hline & $\mathbf{0}$ & $2.500446168850624 \times 10^{-13}$ & $3.997917031149732 \times 10^{-16}$ & $3.428519345071701 \times 10^{-22}$ & 1.29344286891825 \\
\hline & 0.2 & $2.700463948967092 \times 10^{-13}$ & $3.997781031149732 \times 10^{-16}$ & $3.626601056472554 \times 10^{-22}$ & $2.982009645350879 \times 10^{-23}$ \\
\hline & 0.4 & $3.300517289316497 \times 10^{-13}$ & $3.997341031149732 \times 10^{-16}$ & $4.220832590662312 \times 10^{-22}$ & $5.933053221032608 \times 10^{-24}$ \\
\hline & 0.6 & $4.300606189898838 \times 10^{-13}$ & $3.996501031149732 \times 10^{-16}$ & $5.211163547602576 \times 10^{-22}$ & $2.836415786838725 \times 10^{-23}$ \\
\hline & 0.8 & $5.700730650714116 \times 10^{-13}$ & $3.995101031149732 \times 10^{-16}$ & $6.597477927229343 \times 10^{-22}$ & $4.991046909818666 \times 10^{-23}$ \\
\hline & 1 & $7.500890671762329 \times 10^{-13}$ & $3.992917031149732 \times 10^{-16}$ & $8.379546129453018 \times 10^{-22}$ & $3.223603558845966 \times 10^{-23}$ \\
\hline
\end{tabular}

\section{Solving example 5.3 by using the TAM}

To implement the TAM to solve the Eq. (2), we write it in the operator form, as follows

$$
L(w)=w_{t}, \quad N(w)=w_{x x}+w_{y y}+t w(1-w)+u(x, y, t),
$$

with initial condition, $w(x, y, 0)=x^{2}+y^{2}$. 
We start by supposing that $w_{0}$ is an initial approximation of the problem $w$ through solving the following initial equation

$$
L_{t}\left(w_{0}\right)=0, \text { with } w_{0}(x, y, 0)=x^{2}+y^{2}, L_{t}=\frac{\partial}{\partial t} .
$$

Then, we get

$$
w_{0}=x^{2}+y^{2} \text {. }
$$

Also, to get the next iteration, we have to solve the following problem

$$
L_{t}\left(w_{1}\right)+N\left(w_{0}\right)=0 \text {, with } w_{1}(x, y, 0)=x^{2}+y^{2} .
$$

Then, we get

$$
w_{1}=t^{2}-\frac{t^{4}}{4}+\frac{t^{6}}{6}+x^{2}+\frac{t^{4} x^{2}}{2}+y^{2}+\frac{t^{4} y^{2}}{2} .
$$

In the second iteration, we have to solve the following problem

$$
L_{t}\left(w_{2}\right)+N\left(w_{1}\right)=0 \text {, with } w_{2}(x, y, 0)=x^{2}+y^{2} .
$$

Thus, we get

$$
\begin{aligned}
w_{2}=t^{2}+\frac{2 t^{5}}{5} & -\frac{t^{6}}{24}+\frac{t^{8}}{12}-\frac{19 t^{10}}{480}+\frac{t^{12}}{144}-\frac{t^{14}}{504}+x^{2}+\frac{t^{6} x^{2}}{6}-\frac{t^{8} x^{2}}{6}+\frac{t^{10} x^{2}}{40}-\frac{t^{12} x^{2}}{72} \\
& -\frac{t^{6} x^{4}}{6}-\frac{t^{10} x^{4}}{40}+y^{2}+\frac{t^{6} y^{2}}{6}-\frac{t^{8} y^{2}}{6}+\frac{t^{10} y^{2}}{40}-\frac{t^{12} y^{2}}{72}-\frac{1}{3} t^{6} x^{2} y^{2} \\
& -\frac{1}{20} t^{10} x^{2} y^{2}-\frac{t^{6} y^{4}}{6}-\frac{t^{10} y^{4}}{40}
\end{aligned}
$$

$\vdots$

Furthermore, by proceeding in this way the iterations $w_{3}$ and $w_{4}$ were also calculated but for the purpose of brevity is not mentioned here.

To prove the convergence for the TAM for the Eq. (27), we have applied the process as given in Eqs. (15), (16) and (17), and we evaluate the $\delta_{i}$ given in Eq. (19) to check the convergent conditions of the obtained approximate solution. Then, we ge

$$
\begin{aligned}
& \delta_{0}=\frac{\left\|v_{1}\right\|}{\left\|v_{0}\right\|}=0.00005000375008334945<1, \\
& \delta_{1}=\frac{\left\|v_{2}\right\|}{\left\|v_{1}\right\|}=0.00007459982251031754<1, \\
& \delta_{2}=\frac{\left\|v_{3}\right\|}{\left\|v_{2}\right\|}=0.005312373670156887<1, \\
& \delta_{3}=\frac{\left\|v_{4}\right\|}{\left\|v_{3}\right\|}=0.00020729220357214892<1 .
\end{aligned}
$$

The results of $\delta_{i}$, for all $i \geq 0,0<t<1$ and $0 \leq x, y \leq 1$, are less than one. Therefore, the obtained approximate solution by the TAM is converges. 
Also, the absolute error will be calculated with the same values of $\mathrm{x}, \mathrm{t}$ given in solving the problem by using the DJM. It can be seen clearly in Fig. 3 and Table 2 the error is decreasing by increasing the number of iterations. Moreover, the error approximately tends to zero at the fourth iteration with $t=0.001$.

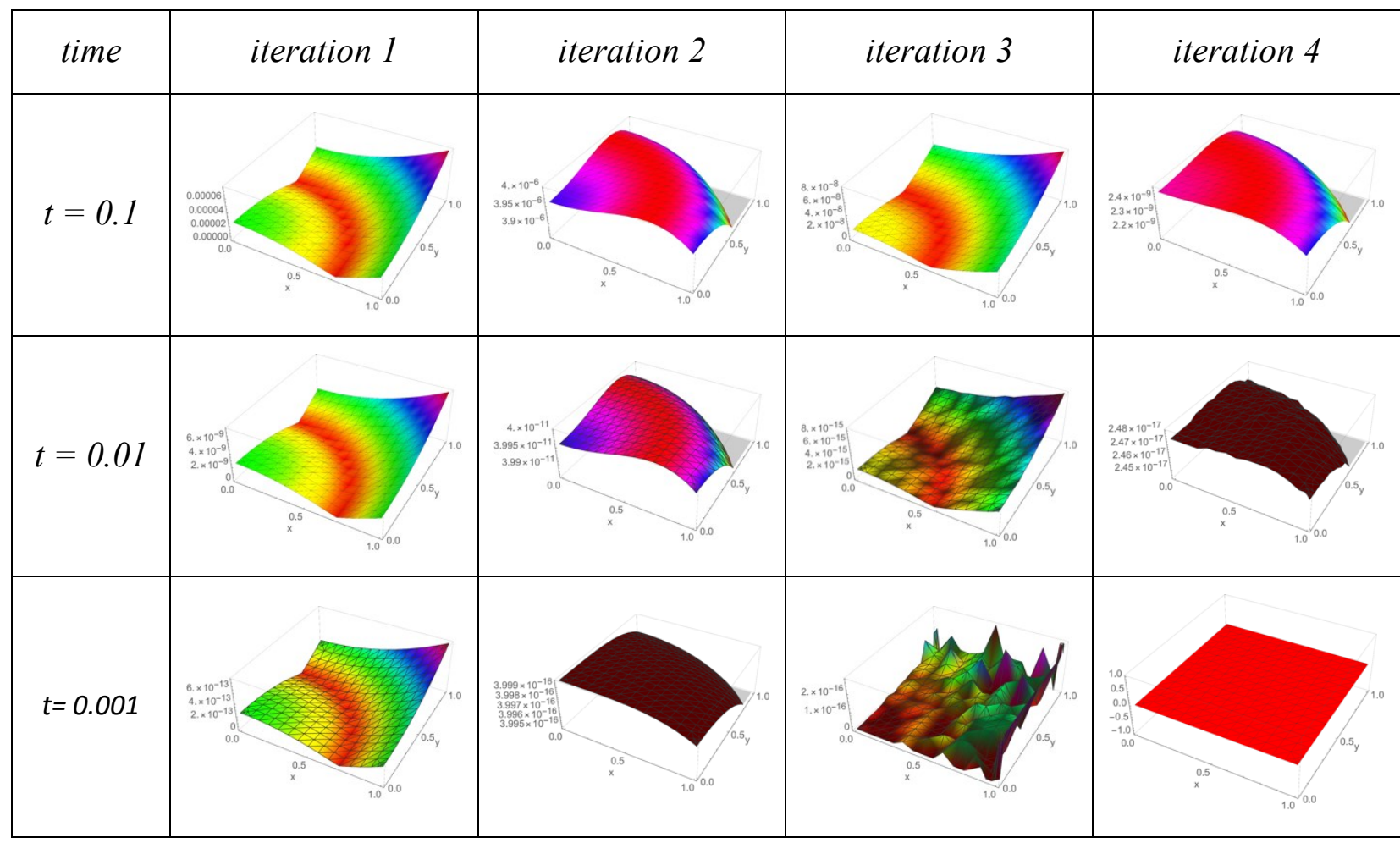

Fig. 3. The absolute error values for example 5.3obtained by the TAM for $w_{1}, w_{2}, w_{3}$, and $w_{4}$ with different values of $t$.

Table 2: The absolute error values for example 5.3 obtained by TAM, for four iterations with different values of $t$.

\begin{tabular}{|c|c|c|c|c|c|}
\hline Time & $x_{i}$ & Abs. errs. For $1^{\text {stiteration }}$ & Abs. errs. For $2^{\text {nd }}$ iteration & Abs. errs. For $3^{\text {rd iteration }}$ & Abs. errs. For $4^{\text {th }}$ iteration \\
\hline \multirow[t]{6}{*}{$t=0.1$} & $\mathbf{0}$ & 0.00002516666666677221 & 0.0000039574960347114 & $3.439519623976705 \times 10^{-8}$ & $2.367214167742215 \times 10^{-9}$ \\
\hline & 0.2 & 0.000027166666666776434 & 0.000003950495930156153 & $3.636235775678065 \times 10^{-8}$ & $2.352566464552952 \times 10^{-9}$ \\
\hline & 0.4 & 0.000033166666666789095 & 0.000003926295568490412 & $4.225011396297162 \times 10^{-8}$ & $2.303341833237437 \times 10^{-9}$ \\
\hline & 0.6 & 0.0000431666666668102 & 0.00000387529480571418 & $5.200767994040234 \times 10^{-8}$ & $2.20374528521472 \times 10^{-9}$ \\
\hline & 0.8 & 0.00005716666666683975 & 0.000003781493401827455 & $6.551841491564403 \times 10^{-8}$ & $2.027660084974458 \times 10^{-9}$ \\
\hline & 1 & 0.00007516666666687773 & 0.000003622491020830237 & $8.255182026850605 \times 10^{-8}$ & $1.739110619403128 \times 10^{-9}$ \\
\hline \multirow[t]{7}{*}{$t=0.01$} & $x_{i}$ & Abs. errs. For $1^{\text {stiteration }}$ & Abs. errs. For $2^{\text {nd }}$ iteration & Abs. errs. For $3^{\text {rd }}$ iteration & Abs. errs. For $4^{\text {th }}$ iteration \\
\hline & $\mathbf{0}$ & $2.500166636275423 \times 10^{-9}$ & $3.995843050700178 \times 10^{-11}$ & $3.341687278453353 \times 10^{-15}$ & $2.465204689688915 \times 10^{-17}$ \\
\hline & 0.2 & $2.700166635059928 \times 10^{-9}$ & $3.995150072691333 \times 10^{-11}$ & $3.760880495917718 \times 10^{-15}$ & $2.463849436973309 \times 10^{-17}$ \\
\hline & 0.4 & $3.300166631413446 \times 10^{-9}$ & $3.992751138664317 \times 10^{-11}$ & $4.32986979603811 \times 10^{-15}$ & $2.461138931542095 \times 10^{-17}$ \\
\hline & 0.6 & $4.300166625335975 \times 10^{-9}$ & $3.987686248617691 \times 10^{-11}$ & $5.329070518200751 \times 10^{-15}$ & $2.448941657101633 \times 10^{-17}$ \\
\hline & 0.8 & $5.700166616827516 \times 10^{-9}$ & $3.978355402549054 \times 10^{-11}$ & $6.439293542825908 \times 10^{-15}$ & $2.434033877229957 \times 10^{-17}$ \\
\hline & 1 & $7.500166605888068 \times 10^{-9}$ & $3.962518600455048 \times 10^{-11}$ & $8.215650382226158 \times 10^{-15}$ & $2.401507812055392 \times 10^{-17}$ \\
\hline \multirow[t]{7}{*}{$t=0.001$} & $x_{i}$ & Abs. errs. For $1^{\text {stiteration }}$ & Abs. errs. For $2^{\text {nd }}$ iteration & Abs. errs. For $3^{\text {rditeration }}$ & Abs. errs. For $4^{\text {th }}$ iteration \\
\hline & $\mathbf{0}$ & $2.500446168850624 \times 10^{-13}$ & $3.997917031149732 \times 10^{-16}$ & $1.39778012230615 \times 10^{-16}$ & 0. \\
\hline & 0.2 & $2.700463948967092 \times 10^{-13}$ & $3.997781031149732 \times 10^{-16}$ & $5.551115123125783 \times 10^{-17}$ & 0. \\
\hline & 0.4 & $3.300517289316497 \times 10^{-13}$ & $3.997341031149732 \times 10^{-16}$ & $2.775557561562891 \times 10^{-17}$ & 0. \\
\hline & 0.6 & $4.300606189898838 \times 10^{-13}$ & $3.996501031149732 \times 10^{-16}$ & $1.665334536937734 \times 10^{-16}$ & 0. \\
\hline & 0.8 & $5.700730650714116 \times 10^{-13}$ & $3.995101031149732 \times 10^{-16}$ & $1.110223024625156 \times 10^{-16}$ & 0. \\
\hline & 1 & $7.500890671762329 \times 10^{-13}$ & $3.992917031149732 \times 10^{-16}$ & $2.220446049250313 \times 10^{-16}$ & 0. \\
\hline
\end{tabular}




\section{Solving example 5.3 by using the BCM}

To implement the BCM to solve the Eq. (2), by following the same steps as in the DJM, we obtain Eq. (29).

Also, suppose

$$
g=x^{2}+y^{2}, \text { and } N(w)=L_{t}^{-1} N(w),
$$

where, $L_{t}^{-1}(\cdot)=\int_{0}^{t}(\cdot) d t, N(w)=w_{x x}+w_{y y}+t w(1-w)+u(x, y, t)$.

Applying the steps of the BCM, we get

$$
\begin{aligned}
& w_{0}=g=x^{2}+y^{2}, \\
& w_{n}=w_{0}+N\left(w_{n-1}\right), n \in \mathbb{N} .
\end{aligned}
$$

Hence,

$$
\begin{aligned}
w_{1}=t^{2}-\frac{t^{4}}{4}+ & \frac{t^{6}}{6}+x^{2}+\frac{t^{4} x^{2}}{2}+y^{2}+\frac{t^{4} y^{2}}{2} \\
w_{2}=t^{2}+\frac{2 t^{5}}{5} & -\frac{t^{6}}{24}+\frac{t^{8}}{12}-\frac{19 t^{10}}{480}+\frac{t^{12}}{144}-\frac{t^{14}}{504}+x^{2}+\frac{t^{6} x^{2}}{6}-\frac{t^{8} x^{2}}{6}+\frac{t^{10} x^{2}}{40}-\frac{t^{12} x^{2}}{72} \\
& -\frac{t^{6} x^{4}}{6}-\frac{t^{10} x^{4}}{40}+y^{2}+\frac{t^{6} y^{2}}{6}-\frac{t^{8} y^{2}}{6}+\frac{t^{10} y^{2}}{40}-\frac{t^{12} y^{2}}{72}-\frac{1}{3} t^{6} x^{2} y^{2} \\
& -\frac{1}{20} t^{10} x^{2} y^{2}-\frac{t^{6} y^{4}}{6}-\frac{t^{10} y^{4}}{40}
\end{aligned}
$$

$\vdots$

Furthermore, by proceeding in this way the iterations $w_{3}$ and $w_{4}$ were also calculated but for the purpose of brevity is not mentioned here.

To prove the convergence analysis of the BCM for the Eq. (27), we have applied the similar process as presented in section 4 and then, we evaluate the $\delta_{i}$ to check the convergent conditions of the obtained approximate solution. Thus, we get

$\delta_{0}=\frac{\left\|v_{1}\right\|}{\left\|v_{0}\right\|}=0.00005000375008334945<1$,

$\delta_{1}=\frac{\left\|v_{2}\right\|}{\left\|v_{1}\right\|}=0.00007459982251031754<1$,

$\delta_{2}=\frac{\left\|v_{3}\right\|}{\left\|v_{2}\right\|}=0.0053123909674375296<1$,

$\delta_{3}=\frac{\left\|v_{4}\right\|}{\left\|v_{3}\right\|}=0.00020887885059192363<1$.

The results of $\delta_{i}$, for all $i \geq 0,0<t<1$ and $0 \leq x, y \leq 1$, are less than one. Therefore, the obtained approximate solution is converges.

Also, the absolute errors will be calculated to check out the efficiency for the approximate solutions that we found by the BCM for the same values of $x, t$ used in the DJM 
and TAM. It can be observed from Fig. 4 and Table 3 the absolute error values obtained by $\mathrm{BCM}$ is decreasing by increasing the number of iterations and decreasing the time.

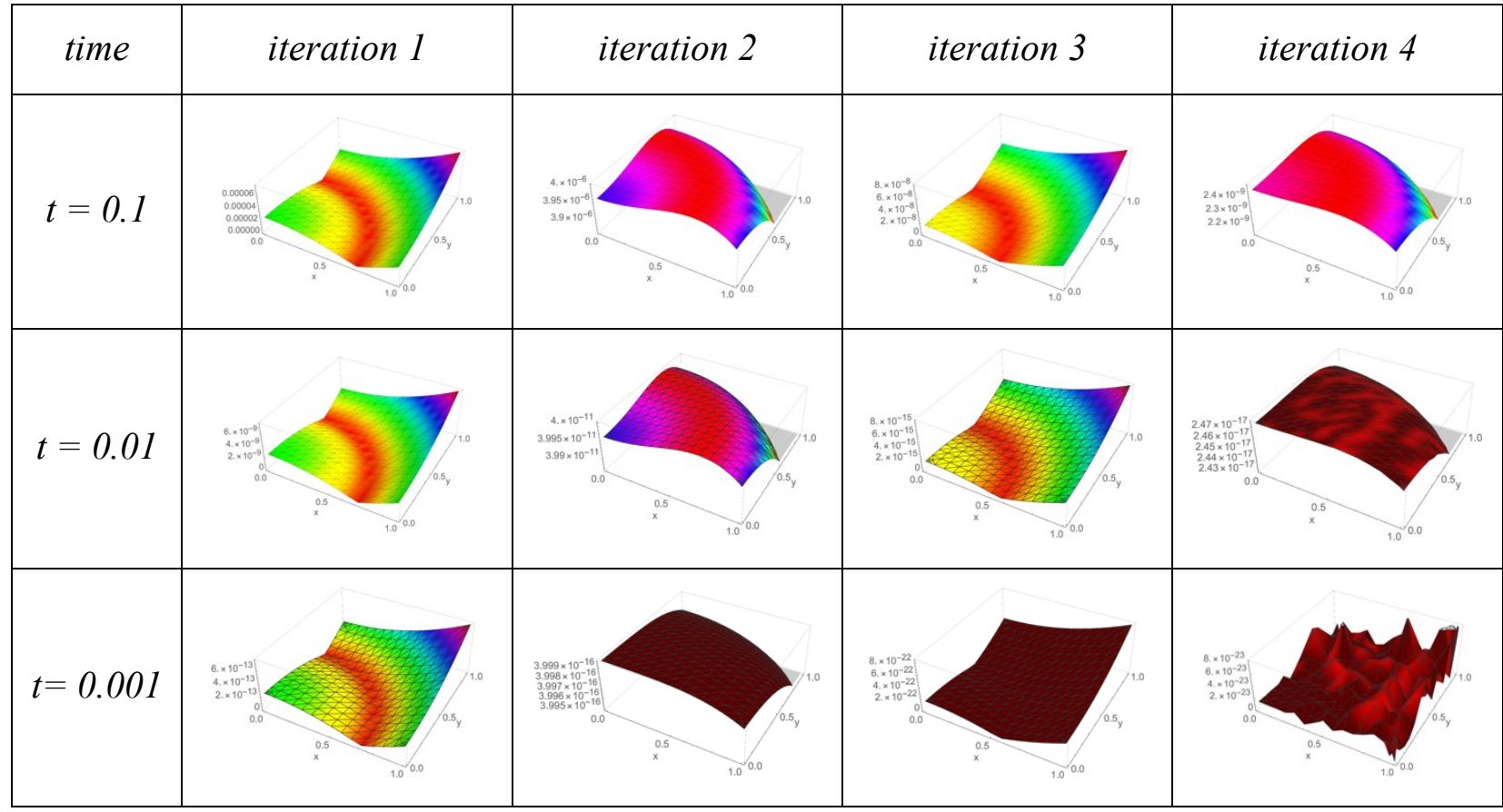

Fig. 4. The absolute error values for example 5.3 obtained by the BCM for $w_{1}, w_{2}, w_{3}$, and $w_{4}$ with different values of $t$.

Table 3: The absolute error values for example 5.3 obtained by BCM, for four iterations with different values of $t$.

\begin{tabular}{|c|c|c|c|c|c|}
\hline Time & $\overline{x_{i}}$ & Abs. errs. For $1^{\text {st }}$ iteration & Abs. errs. For $2^{\text {nd }}$ iteration & Abs. errs. For $3^{\text {rd }}$ iteration & Abs. errs. For $4^{\text {th }}$ iteration \\
\hline \multirow[t]{6}{*}{$t=0.1$} & $\mathbf{0}$ & 0.00002516666666677221 & 0.0000039574960347114 & $3.439519622754291 \times 10^{-8}$ & $2.367214207006091 \times 10^{-9}$ \\
\hline & 0.2 & 0.000027166666666776434 & 0.000003950495930156153 & $3.636235764046649 \times 10^{-8}$ & $2.352566504062037 \times 10^{-9}$ \\
\hline & 0.4 & 0.000033166666666789095 & 0.000003926295568490412 & $4.225011372322602 \times 10^{-8}$ & $2.303341876975943 \times 10^{-9}$ \\
\hline & 0.6 & 0.0000431666666668102 & 0.00000387529480571418 & $5.200767991296621 \times 10^{-8}$ & $2.203745339426222 \times 10^{-9}$ \\
\hline & 0.8 & 0.00005716666666683975 & 0.000003781493401827455 & $6.551841495654667 \times 10^{-8}$ & $2.027660150299521 \times 10^{-9}$ \\
\hline & 1 & 0.00007516666666687773 & 0.000003622491020830237 & $8.255182044155353 \times 10^{-8}$ & $1.739110699410879 \times 10^{-9}$ \\
\hline \multirow[t]{7}{*}{$t=0.01$} & $\overline{x_{i}}$ & Abs. errs. For $1^{\text {st }}$ iteration & Abs. errs. For $2^{\text {nd }}$ iteration & Abs. errs. For $3^{\text {rd }}$ iteration & Abs. errs. For $4^{\text {th }}$ iteration \\
\hline & $\mathbf{0}$ & 2.5001666362 & $3.995843050700178 \times 10^{-11}$ & $3.428213061620738 \times 10^{-15}$ & $2.459218564137952 \times 10^{-17}$ \\
\hline & 0.2 & 2.7001666350 & $3.995150072691333 \times 10^{-11}$ & $3.626173005459958 \times 10^{-15}$ & $2.45742245436945 \times 10^{-17}$ \\
\hline & 0.4 & $3.300166631413446 \times 10^{-9}$ & $3.992751138664317 \times 10^{-11}$ & $4.219916824177479 \times 10^{-15}$ & $2.451761901624386 \times 10^{-17}$ \\
\hline & 0.6 & $4.300166625335975 \times 10^{-9}$ & $3.987686248617691 \times 10^{-11}$ & $5.208940479372794 \times 10^{-15}$ & $2.441165215801239 \times 10^{-17}$ \\
\hline & 0.8 & $5.700166616827516 \times 10^{-9}$ & $3.978355402549054 \times 10^{-11}$ & $6.592083907044729 \times 10^{-15}$ & $2.421667439210999 \times 10^{-17}$ \\
\hline & 1 & $7.500166605888068 \times 10^{-9}$ & $3.962518600455048 \times 10^{-11}$ & $8.367051017590978 \times 10^{-15}$ & $2.391594246117009 \times 10^{-17}$ \\
\hline \multirow[t]{7}{*}{$t=0.001$} & $x_{i}$ & Abs. errs. For $1^{\text {stiteration }}$ & Abs. errs. For $2^{\text {nd }}$ iteration & Abs. errs. For $3^{\text {rditeration }}$ & Abs. errs. For $4^{\text {th }}$ iteration \\
\hline & $\mathbf{0}$ & $2.500446168850624 \times 10^{-13}$ & $3.997917031149732 \times 10^{-16}$ & $3.428519345071701 \times 10^{-22}$ & $1.29344286891825 \times 10^{-23}$ \\
\hline & 0.2 & $2.700463948967092 \times 10^{-13}$ & $3.997781031149732 \times 10^{-16}$ & $3.626601056472554 \times 10^{-22}$ & $2.982009645350879 \times 10^{-23}$ \\
\hline & 0.4 & $3.300517289316497 \times 10^{-13}$ & $3.997341031149732 \times 10^{-16}$ & $4.220832590662312 \times 10^{-22}$ & $5.933053221032608 \times 10^{-24}$ \\
\hline & 0.6 & $4.300606189898838 \times 10^{-13}$ & $3.996501031149732 \times 10^{-16}$ & $5.211163547602576 \times 10^{-22}$ & $2.836415786838725 \times 10^{-23}$ \\
\hline & 0.8 & $5.700730650714116 \times 10^{-13}$ & $3.995101031149732 \times 10^{-16}$ & $6.597477927229343 \times 10^{-22}$ & $4.991046909818666 \times 10^{-23}$ \\
\hline & 1 & $7.500890671762329 \times 10^{-13}$ & $3.992917031149732 \times 10^{-16}$ & $8.379546129453018 \times 10^{-22}$ & $3.223603558845966 \times 10^{-23}$ \\
\hline
\end{tabular}

Example 5.4. Consider the 3D Fisher's equation given in Eq. (3), with $\alpha=\beta=1$, as follows

$$
w_{t}=w_{x x}+w_{y y}+w_{z z}+t w(1-w)+u(x, y, z, t),
$$


and the initial condition, $w(x, y, z, 0)=x^{3}+y^{3}+z^{3}$,

where, $u(x, y, z, t)=3 t^{2}-6 x-6 y-6 z-t\left(1-t^{3}-x^{3}-y^{3}-z^{3}\right)\left(t^{3}+x^{3}+y^{3}+z^{3}\right)$.

The exact solution for this equation is

$$
w=x^{3}+y^{3}+z^{3}+t^{3} .
$$

\section{Solving example 5.4 by using the DJM}

To implement the DJM for solving the Eq.(30), we write it in the operator form as follows

$$
L_{t}(w(x, y, z, t))=N(w)
$$

where, $L_{t}=\frac{\partial}{\partial t}$ and $N(w)=w_{x x}+w_{y y}+w_{z z}+t w(1-w)+u(x, y, z, t)$.

By taking the inverse for together sides of Eq. (31), and applying the initial condition, we obtain

$$
w=\left(x^{3}+y^{3}+z^{3}\right)+L_{t}^{-1} N(w) .
$$

Finally, according to the DJM for Eq. (32) and by applying the recurrence relation, we achieve the components $w_{n}$ as the following in a series form

$$
\begin{aligned}
& w_{0}=x^{3}+y^{3}+z^{3}, \\
& w_{1}=L_{t}^{-1}\left(J_{0}\right)=L_{t}^{-1} N\left(w_{0}\right)=t^{3}-\frac{t^{5}}{5}+\frac{t^{8}}{8}+\frac{2 t^{5} x^{3}}{5}+\frac{2 t^{5} y^{3}}{5}+\frac{2 t^{5} z^{3}}{5}, \\
& w_{2}=L_{t}^{-1}\left(J_{1}\right)=L_{t}^{-1} N\left(w_{0}+w_{1}\right)-w_{1} \\
& \quad=\frac{t^{5}}{5}-\frac{t^{7}}{35}-\frac{t^{8}}{8}+\frac{21 t^{10}}{400}-\frac{t^{12}}{300}-\frac{t^{13}}{52}+\frac{t^{15}}{300}-\frac{t^{18}}{1152}+\frac{2 t^{6} x}{5}-\frac{2 t^{5} x^{3}}{5}+\frac{4 t^{7} x^{3}}{35}- \\
& \frac{21 t^{10} x^{3}}{200}+\frac{t^{12} x^{3}}{75}-\frac{t^{15} x^{3}}{150}-\frac{4 t^{7} x^{6}}{35}-\frac{t^{12} x^{6}}{75}+\frac{2 t^{6} y}{5}-\frac{2 t^{5} y^{3}}{5}+\frac{4 t^{7} y^{3}}{35}-\frac{21 t^{10} y^{3}}{200}+\frac{t^{12} y^{3}}{75}-\frac{t^{15} y^{3}}{150}- \\
& \frac{8}{35} t^{7} x^{3} y^{3}-\frac{2}{75} t^{12} x^{3} y^{3}-\frac{4 t^{7} y^{6}}{35}-\frac{t^{12} y^{6}}{75}+\frac{2 t^{6} z}{5}-\frac{2 t^{5} z^{3}}{5}+\frac{4 t^{7} z^{3}}{35}-\frac{21 t^{10} z^{3}}{200}+\frac{t^{12} z^{3}}{75}-\frac{t^{15} z^{3}}{150}- \\
& \frac{8}{35} t^{7} x^{3} z^{3}-\frac{2}{75} t^{12} x^{3} z^{3}-\frac{8}{35} t^{7} y^{3} z^{3}-\frac{2}{75} t^{12} y^{3} z^{3}-\frac{4 t^{7} z^{6}}{35}-\frac{t^{12} z^{6}}{75},
\end{aligned}
$$$$
\vdots
$$

By continuing in this way the iterations $w_{3}$ and $w_{4}$ were also calculated but for the purpose of brevity is not mentioned here.

To prove the convergence of the DJM for the Eq. (30), we have applied the process as presented in section 4 . Hence, let choose the same above components obtained by the DJM, we get

$$
\begin{aligned}
& v_{0}=w_{0}=x^{3}+y^{3}+z^{3} \\
& v_{1}=w_{1}=t^{3}-\frac{t^{5}}{5}+\frac{t^{8}}{8}+\frac{2 t^{5} x^{3}}{5}+\frac{2 t^{5} y^{3}}{5}+\frac{2 t^{5} z^{3}}{5},
\end{aligned}
$$


and so on, by using the iterations above and we evaluate the $\delta_{i}$ given in Eq. (19) to check the convergent conditions of the obtained approximate solution, then, we get

$\delta_{0}=\frac{\left\|v_{1}\right\|}{\left\|v_{0}\right\|}=3.333666666708334 \times 10^{-7}<1$,

$\delta_{1}=\frac{\left\|v_{2}\right\|}{\left\|v_{1}\right\|}=0.00009879727563096987<1$,

$\delta_{2}=\frac{\left\|v_{3}\right\|}{\left\|v_{2}\right\|}=0.012075415524177402<1$,

$\delta_{3}=\frac{\left\|v_{4}\right\|}{\left\|v_{3}\right\|}=0.0002323087617440097<1$.

The results of $\delta_{i}$, for all $i \geq 0,0<t<1$ and $0 \leq x, y, z \leq 1$, are less than one. Therefore, the approximate solution obtained by the DJM is converges.

Also, the absolute errors are calculated to check out the efficiency for the approximate solutions for various values of the time $t=0.1,0.01$ and 0.001 , given in Fig. 5. Moreover, Table 4 shows the absolute error values obtained by DJM for the iterations with $x=$ $\{0,0.2,0.4,0.6,0.8,1\}$, it can be easily recognized that the error is decreasing by increasing the number of iterations and decreasing the value of time.

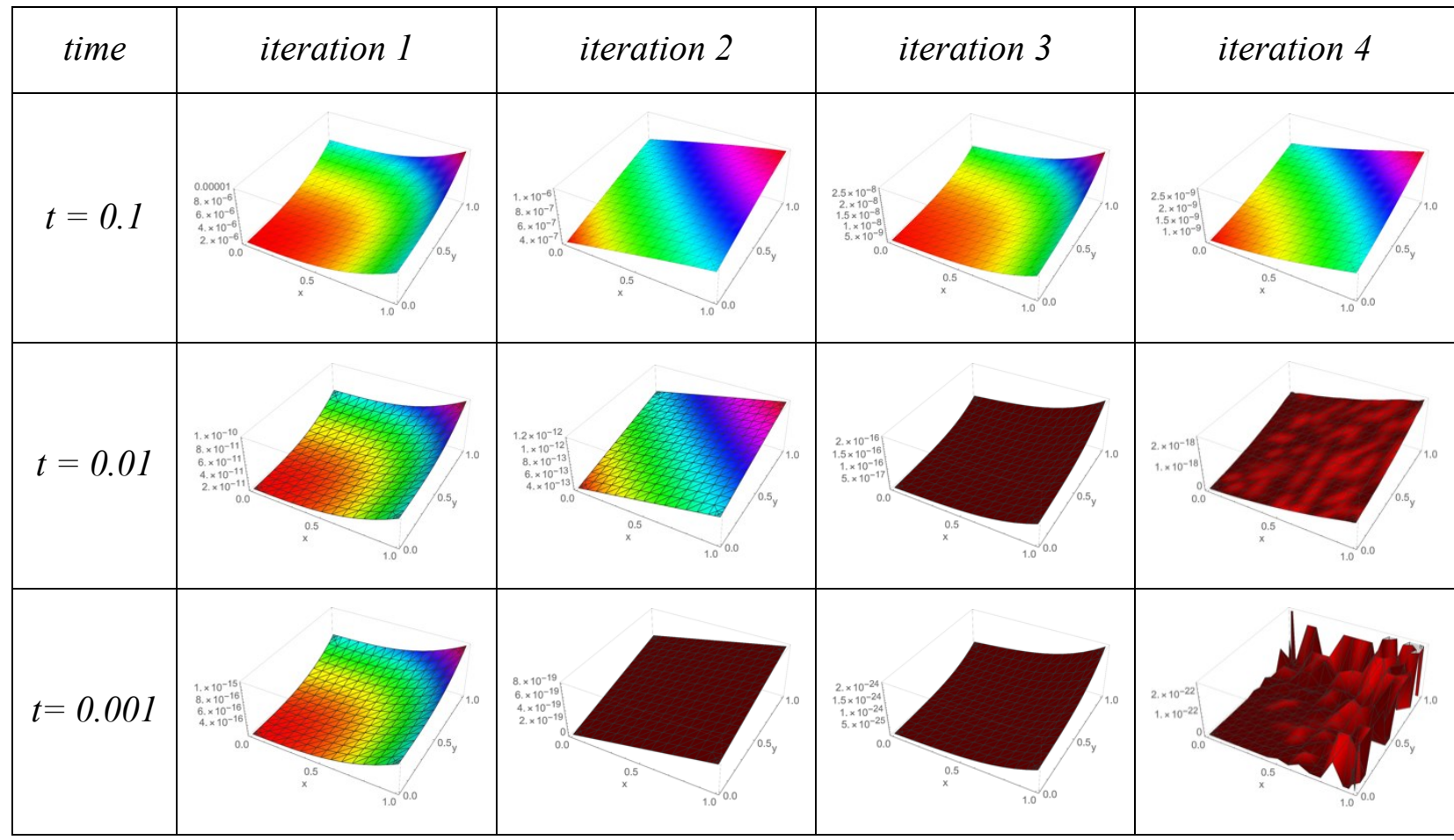

Fig. 5. The absolute error values for example 5.4 obtained by the DJM for $w_{1}, w_{2}, w_{3}$, and $w_{4}$ with different values of $t$. 
Table 4: The absolute error values for example 5.4 obtained by DJM, for four iterations with different values of $t$.

\begin{tabular}{|c|c|c|c|c|c|}
\hline Time & $x_{i}$ & Abs. errs. For $1^{\text {st }}$ iteration & Abs. errs. For $2^{\text {nd }}$ iteration & Abs. errs. For $3^{\text {rd }}$ iteration & Abs. errs. For $4^{\text {th }}$ iteration \\
\hline \multirow[t]{6}{*}{$t=0.1$} & $\mathbf{0}$ & 0.00000600124999983187 & $7.742699323627617 \times 10^{-7}$ & $1.320252550675336 \times 10^{-8}$ & $1.67004493323643 \times 10^{-9}$ \\
\hline & 0.2 & 0.000006033249999831014 & $8.539948308988224 \times 10^{-7}$ & $1.406757778557003 \times 10^{-8}$ & $1.837622725104753 \times 10^{-9}$ \\
\hline & 0.4 & 0.000006257249999825021 & $9.320281606034605 \times 10^{-7}$ & $1.530290758255603 \times 10^{-8}$ & $2.05549086807278 \times 10^{-9}$ \\
\hline & 0.6 & 0.000006865249999808754 & 0.000001006328729380217 & $1.746112293136207 \times 10^{-8}$ & $2.314295728200713 \times 10^{-9}$ \\
\hline & 0.8 & 0.000008049249999777076 & 0.000001073714315230005 & $2.128396463294381 \times 10^{-8}$ & $2.597436775633328 \times 10^{-9}$ \\
\hline & 1 & 0.000010001249999724848 & 0.000001128545093286537 & $2.767829010265537 \times 10^{-8}$ & $2.872778668825741 \times 10^{-9}$ \\
\hline \multirow[t]{7}{*}{$t=0.01$} & $x_{i}$ & Abs. errs. For $1^{\text {st }}$ iteration & Abs. errs. For $2^{\text {nd }}$ iteration & Abs. errs. For $3^{\text {rditeration }}$ & Abs. errs. For $4^{\text {th }}$ iteration \\
\hline & $\mathbf{0}$ & $6.000000496442226 \times 10^{-11}$ & $7.97649253302486 \times 10^{-13}$ & $9.38428773337254 \times 10^{-17}$ & $36 \times 10^{-18}$ \\
\hline & 0.2 & $6.032000499089918 \times 10^{-11}$ & $8.77622012661146 \times 10^{-13}$ & $1.023660726055963 \times 10^{-16}$ & $1.233279971202261 \times 10^{-18}$ \\
\hline & 0.4 & $6.256000517623761 \times 10^{-11}$ & $9.574272321717656 \times 10^{-13}$ & $1.138474363261675 \times 10^{-16}$ & $1.45012040569936 \times 10^{-18}$ \\
\hline & 0.6 & $6.864000567929908 \times 10^{-11}$ & $1.036862409700589 \times 10^{-12}$ & $1.331019827670317 \times 10^{-16}$ & $1.707618421664664 \times 10^{-18}$ \\
\hline & 0.8 & $8.048000665894506 \times 10^{-11}$ & $1.115610940256718 \times 10^{-12}$ & $1.669606053641445 \times 10^{-16}$ & $2.087089182034583 \times 10^{-18}$ \\
\hline & 1 & $1.000000082740371 \times 10^{-10}$ & $1.193110458849249 \times 10^{-12}$ & $2.242460647913282 \times 10^{-16}$ & $2.493664996716629 \times 10^{-18}$ \\
\hline \multirow[t]{7}{*}{$t=0.001$} & $x_{i}$ & Abs. errs. For $1^{\text {st }}$ iteration & Abs. errs. For $2^{\text {nd }}$ iteration & Abs. errs. For $3^{\text {rditeration }}$ & Abs. errs. For $4^{\text {th }}$ iteration \\
\hline & $\mathbf{0}$ & $6.661338147750939 \times 10^{-16}$ & $3.998857142857143 \times 10^{-19}$ & $9.392000002026451 \times 10^{-25}$ & 1.48331235938 \\
\hline & 0.2 & $6.696865284538944 \times 10^{-16}$ & $4.798838784 \times 10^{-19}$ & $1.024444335758498 \times 10^{-24}$ & $2.117582368135751 \times 10^{-22}$ \\
\hline & 0.4 & $6.94555524205498 \times 10^{-16}$ & $5.598706176 \times 10^{-19}$ & $1.139348554054155 \times 10^{-24}$ & $2.117582368135751 \times 10^{-22}$ \\
\hline & 0.6 & $7.620570841027075 \times 10^{-16}$ & $6.398310107428573 \times 10^{-19}$ & $1.332174526510562 \times 10^{-24}$ & $2.117582368135751 \times 10^{-22}$ \\
\hline & 0.8 & $8.93507490218326 \times 10^{-16}$ & $7.197387264 \times 10^{-19}$ & $1.67146743228809 \times 10^{-24}$ & $2.117582368135751 \times 10^{-22}$ \\
\hline & 1 & $1.110223024625156 \times 10^{-15}$ & $7.995428571428572 \times 10^{-19}$ & $2.246031746364245 \times 10^{-24}$ & $3.004975599994815 \times 10^{-47}$ \\
\hline
\end{tabular}

\section{Solving example 5.4 by using the TAM}

To implement the TAM for Eq.(30), we write it in the operator form, as follows

$$
L(w)=w_{t}, \quad N(w)=w_{x x}+w_{y y}+w_{z z}+t w(1-w)+u(x, y, z, t),
$$

with initial condition,

$w(x, y, z, 0)=x^{3}+y^{3}+z^{3}$.

We start by assuming that $w_{0}$ is an initial approximation of the problem $w$ through solving the following initial equation

$$
L_{t}\left(w_{0}\right)=0 \text {, with } w_{0}(x, y, z, 0)=x^{3}+y^{3}+z^{3}, L_{t}=\frac{\partial}{\partial t} .
$$

Then, we get

$$
w_{0}=x^{3}+y^{3}+z^{3} .
$$

Also, to obtain the next iteration, we have to solve the following problem

$$
L_{t}\left(w_{1}\right)+N\left(w_{0}\right)=0 \text {, with } w_{1}(x, y, z, 0)=x^{3}+y^{3}+z^{3} .
$$

Then, we get

$w_{1}=t^{3}-\frac{t^{5}}{5}+\frac{t^{8}}{8}+x^{3}+\frac{2 t^{5} x^{3}}{5}+y^{3}+\frac{2 t^{5} y^{3}}{5}+z^{3}+\frac{2 t^{5} z^{3}}{5}$.

In the second iteration, we have to solve the following problem

$L_{t}\left(w_{2}\right)+N\left(w_{1}\right)=0$, with $w_{2}(x, y, z, 0)=x^{3}+y^{3}+z^{3}$.

Thus, we get 


$$
\begin{aligned}
w_{2}=t^{3}-\frac{t^{7}}{35} & +\frac{21 t^{10}}{400}-\frac{t^{12}}{300}-\frac{t^{13}}{52}+\frac{t^{15}}{300}-\frac{t^{18}}{1152}+\frac{2 t^{6} x}{5}+x^{3}+\frac{4 t^{7} x^{3}}{35}-\frac{21 t^{10} x^{3}}{200} \\
& +\frac{t^{12} x^{3}}{75}-\frac{t^{15} x^{3}}{150}-\frac{4 t^{7} x^{6}}{35}-\frac{t^{12} x^{6}}{75}+\frac{2 t^{6} y}{5}+y^{3}+\frac{4 t^{7} y^{3}}{35}-\frac{21 t^{10} y^{3}}{200}+\frac{t^{12} y^{3}}{75} \\
& -\frac{t^{15} y^{3}}{150}-\frac{8}{35} t^{7} x^{3} y^{3}-\frac{2}{75} t^{12} x^{3} y^{3}-\frac{4 t^{7} y^{6}}{35}-\frac{t^{12} y^{6}}{75}+\frac{2 t^{6} z}{5}+z^{3}+\frac{4 t^{7} z^{3}}{35} \\
& -\frac{21 t^{10} z^{3}}{200}+\frac{t^{12} z^{3}}{75}-\frac{t^{15} z^{3}}{150}-\frac{8}{35} t^{7} x^{3} z^{3}-\frac{2}{75} t^{12} x^{3} z^{3}-\frac{8}{35} t^{7} y^{3} z^{3} \\
& -\frac{2}{75} t^{12} y^{3} z^{3}-\frac{4 t^{7} z^{6}}{35}-\frac{t^{12} z^{6}}{75} .
\end{aligned}
$$

$\vdots$

and by continuing in this way the iterations $w_{3}$ and $w_{4}$ were also calculated but for the purpose of brevity is not mentioned here.

To prove the convergence for the TAM for the Eq. (30), we have applied the process as given in Eqs. (15), (16) and (17), and we evaluate the $\delta_{i}$ given in Eq. (19) to check the convergent conditions of the obtained approximate solution.

Then, we get

$$
\begin{aligned}
& \delta_{0}=\frac{\left\|v_{1}\right\|}{\left\|v_{0}\right\|}=3.333666667160173 \times 10^{-7}<1, \\
& \delta_{1}=\frac{\left\|v_{2}\right\|}{\left\|v_{1}\right\|}=0.00009879757291895636<1, \\
& \delta_{2}=\frac{\left\|v_{3}\right\|}{\left\|v_{2}\right\|}=0.012067708416467766<1, \\
& \delta_{3}=\frac{\left\|v_{4}\right\|}{\left\|v_{3}\right\|}=0 .<1 .
\end{aligned}
$$

The results of $\delta_{i}$, for all $i \geq 0,0<t<1$ and $0 \leq \mathrm{x}, \mathrm{y}, \mathrm{z} \leq 1$, are less than one. Therefore, a convergent approximate solution is obtained. Also, the absolute errors are evaluated in similar cases done for the DJM. Fig. 6 and Table 5 show the absolute error values obtained by TAM , it can be easily recognized that the error is decreasing by increasing the number of iterations and deceasing the time. 


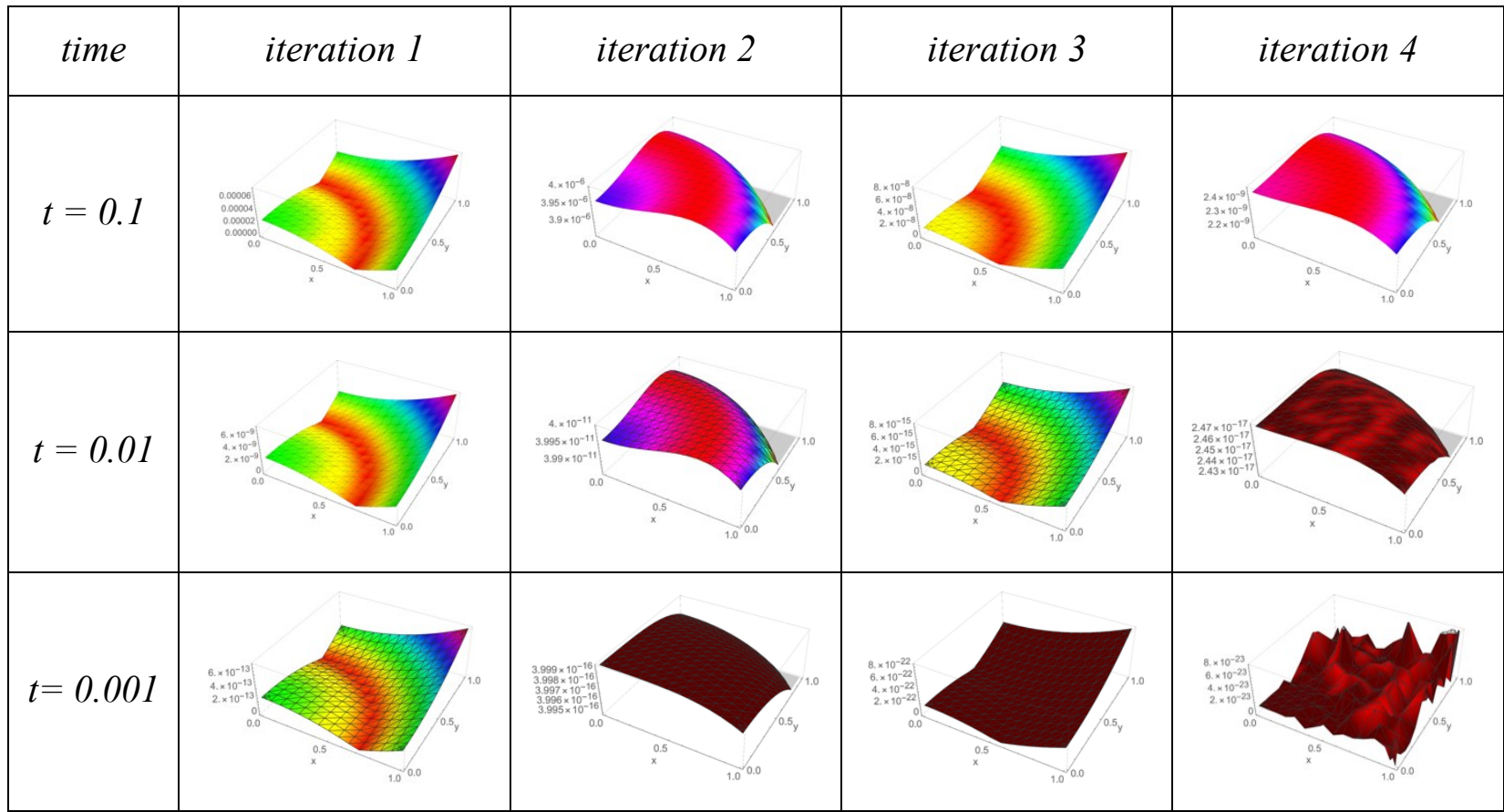

Fig. 6. The absolute error values for example 5.4 obtained by the TAM for $w_{1}, w_{2}, w_{3}$, and $w_{4}$ with different values of $t$

Table 5: The absolute error values for example 5.4 obtained by TAM, for four iterations with different values of $t$.

\begin{tabular}{|c|c|c|c|c|c|}
\hline Time & $\overline{x_{i}}$ & Abs. errs. For $1^{\text {stiteration }}$ & Abs. errs. For $2^{\text {nd }}$ iteration & Abs. errs. For $3^{\text {rd }}$ iteration & Abs. errs. For $4^{\text {th }}$ iteration \\
\hline \multirow[t]{6}{*}{$t=0.1$} & $\mathbf{0}$ & 0.00000600124999983187 & $7.742699323627617 \times 10^{-7}$ & $1.320252529524168 \times 10^{-8}$ & $1.670044996390784 \times 10^{-9}$ \\
\hline & 0.2 & 0.000006033249999831014 & $8.539948308988224 \times 10^{-7}$ & $1.406757776933886 \times 10^{-8}$ & $1.837622790263129 \times 10^{-9}$ \\
\hline & 0.4 & 0.000006257249999825021 & $9.320281606034605 \times 10^{-7}$ & $1.530290782980614 \times 10^{-8}$ & $2.055490934144838 \times 10^{-9}$ \\
\hline & 0.6 & 0.000006865249999808754 & 0.000001006328729380217 & $1.746112321399096 \times 10^{-8}$ & $2.314295792548229 \times 10^{-9}$ \\
\hline & 0.8 & 0.000008049249999777076 & 0.000001073714315230005 & $2.128396436873458 \times 10^{-8}$ & $2.597436836145397 \times 10^{-9}$ \\
\hline & 1 & 0.000010001249999724848 & 0.000001128545093286537 & $2.767828988226028 \times 10^{-8}$ & $2.872778724757538 \times 10^{-9}$ \\
\hline \multirow[t]{7}{*}{$t=0.01$} & $x_{i}$ & Abs. errs. For $1^{\text {stiteration }}$ & Abs. errs. For $2^{\text {nd }}$ iteration & Abs. errs. For $3^{\text {rditeration }}$ & Abs. errs. For $4^{\text {th }}$ iteration \\
\hline & $\mathbf{0}$ & $6.000000496442226 \times 10^{-11}$ & $7.97649253302486 \times 10^{-13}$ & $2.220446049250313 \times 10^{-16}$ & $8.050561119707455 \times 10^{-17}$ \\
\hline & 0.2 & $6.032000499089918 \times 10^{-11}$ & $8.77622012661146 \times 10^{-13}$ & $2.220446049250313 \times 10^{-16}$ & $8.033323999230829 \times 10^{-17}$ \\
\hline & 0.4 & $6.256000517623761 \times 10^{-11}$ & $9.574272321717656 \times 10^{-13}$ & $2.220446049250313 \times 10^{-16}$ & $8.010475285478645 \times 10^{-17}$ \\
\hline & 0.6 & $6.864000567929908 \times 10^{-11}$ & $1.036862409700589 \times 10^{-12}$ & $4.440892098500626 \times 10^{-16}$ & $7.982205560864032 \times 10^{-17}$ \\
\hline & 0.8 & $8.048000665894506 \times 10^{-11}$ & $1.115610940256718 \times 10^{-12}$ & 0. & $7.948578352858036 \times 10^{-17}$ \\
\hline & 1 & $1.000000082740371 \times 10^{-10}$ & $1.193110458849249 \times 10^{-12}$ & 0. & $7.909974826286921 \times 10^{-17}$ \\
\hline \multirow[t]{7}{*}{$t=0.001$} & $x_{i}$ & Abs. errs. For $1^{\text {stiteration }}$ & Abs. errs. For $2^{\text {nd }}$ iteration & Abs. errs. For $3^{\text {rditeration }}$ & Abs. errs. For $4^{\text {th }}$ iteration \\
\hline & $\mathbf{0}$ & $6.661338147750939 \times 10^{-16}$ & $3.998857142857143 \times 10^{-19}$ & 0. & $8.274037093680878 \times 10^{-17}$ \\
\hline & 0.2 & $6.696865284538944 \times 10^{-16}$ & $4.798838784 \times 10^{-19}$ & 0. & $8.274037093680878 \times 10^{-17}$ \\
\hline & 0.4 & $6.94555524205498 \times 10^{-16}$ & $5.598706176 \times 10^{-19}$ & 0. & $8.274037093680878 \times 10^{-17}$ \\
\hline & 0.6 & $7.620570841027075 \times 10^{-16}$ & $6.398310107428573 \times 10^{-19}$ & 0. & $8.274037093680878 \times 10^{-17}$ \\
\hline & 0.8 & $8.93507490218326 \times 10^{-16}$ & $7.197387264 \times 10^{-19}$ & 0. & $8.274037093680878 \times 10^{-17}$ \\
\hline & 1 & $1.110223024625156 \times 10^{-15}$ & $7.995428571428572 \times 10^{-19}$ & 0. & $8.274037093680878 \times 10^{-17}$ \\
\hline
\end{tabular}

\section{Solving example 5.4 by using the BCM}

To implement the BCM to solve the Eq. (30), we followed similar steps as given for the DJM, we obtain Eq. (32).

Also, suppose 


$$
g=x^{3}+y^{3}+z^{3}, \text { and } N(w)=L_{t}^{-1} N(w),
$$

Where,

$$
L_{t}^{-1}(\cdot)=\int_{0}^{t}(\cdot) d t, N(w)=w_{x x}+w_{y y}+w_{z z}+t w(1-w)+u(x, y, z, t) .
$$

Applying the steps of the BCM, we get

$w_{0}=g=x^{3}+y^{3}+z^{3}$,

$w_{n}=w_{0}+N\left(w_{n-1}\right), n \in \mathbb{N}$.

Hence,

$w_{1}=t^{3}-\frac{t^{5}}{5}+\frac{t^{8}}{8}+x^{3}+\frac{2 t^{5} x^{3}}{5}+y^{3}+\frac{2 t^{5} y^{3}}{5}+z^{3}+\frac{2 t^{5} z^{3}}{5}$,

$w_{2}=t^{3}-\frac{t^{7}}{35}+\frac{21 t^{10}}{400}-\frac{t^{12}}{300}-\frac{t^{13}}{52}+\frac{t^{15}}{300}-\frac{t^{18}}{1152}+\frac{2 t^{6} x}{5}+x^{3}+\frac{4 t^{7} x^{3}}{35}-\frac{21 t^{10} x^{3}}{200}+\frac{t^{12} x^{3}}{75}-$

$\frac{t^{15} x^{3}}{150}-\frac{4 t^{7} x^{6}}{35}-\frac{t^{12} x^{6}}{75}+\frac{2 t^{6} y}{5}+y^{3}+\frac{4 t^{7} y^{3}}{35}-\frac{21 t^{10} y^{3}}{200}+\frac{t^{12} y^{3}}{75}-\frac{t^{15} y^{3}}{150}-\frac{8}{35} t^{7} x^{3} y^{3}-$

$\frac{2}{75} t^{12} x^{3} y^{3}-\frac{4 t^{7} y^{6}}{35}-\frac{t^{12} y^{6}}{75}+\frac{2 t^{6} z}{5}+z^{3}+\frac{4 t^{7} z^{3}}{35}-\frac{21 t^{10} z^{3}}{200}+\frac{t^{12} z^{3}}{75}-\frac{t^{15} z^{3}}{150}-\frac{8}{35} t^{7} x^{3} z^{3}-$

$\frac{2}{75} t^{12} x^{3} z^{3}-\frac{8}{35} t^{7} y^{3} z^{3}-\frac{2}{75} t^{12} y^{3} z^{3}-\frac{4 t^{7} z^{6}}{35}-\frac{t^{12} z^{6}}{75}$,

$\vdots$

and the iterations $w_{3}$ and $w_{4}$ were also calculated but for the purpose of brevity is not mentioned here.

To prove the convergence of the BCM for the Eq. (30), we have applied the similar procedure as presented in section 4 and then, we evaluate the $\delta_{i}$ to check the convergent conditions of the obtained approximate solution.

Then, we get

$\delta_{0}=\frac{\left\|v_{1}\right\|}{\left\|v_{0}\right\|}=3.333666667160173 \times 10^{-7}<1$,

$\delta_{1}=\frac{\left\|v_{2}\right\|}{\left\|v_{1}\right\|}=0.00009879757291895636<1$,

$\delta_{2}=\frac{\left\|v_{3}\right\|}{\left\|v_{2}\right\|}=0.012071065747678055<1$,

$\delta_{3}=\frac{\left\|v_{4}\right\|}{\left\|v_{3}\right\|}=0.00012935399757212153<1$.

The results of $\delta_{i}$, for all $i \geq 0,0<t<1$ and $0 \leq x, y, z \leq 1$, are less than one. Therefore, the obtained approximate solution by the BCM is converges.

Fig. 7 and Table 6 show the absolute error values obtained by BCM, it can be easily recognized that the error is decreasing by increasing the number of iterations and decreasing the time. 


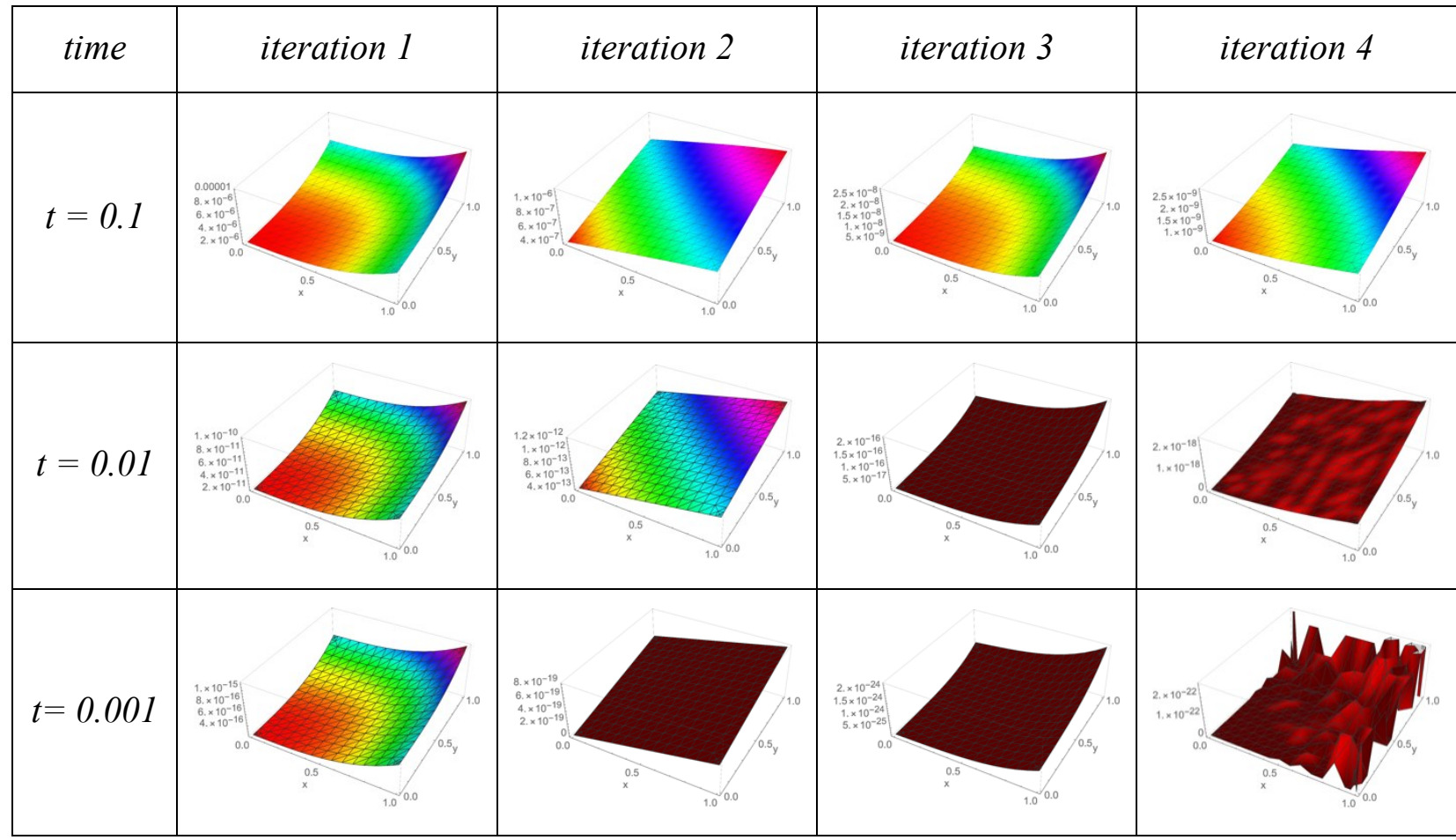

Fig. 7. The absolute error values for example 5.4 obtained by the BCM for $w_{1}, w_{2}, w_{3}$, and $w_{4}$ with different values of $t$.

Table 6: The absolute error values for example 5.4 obtained by BCM, for four iterations with different values of $t$.

\begin{tabular}{|c|c|c|c|c|c|}
\hline Time & $\overline{x_{i}}$ & Abs. errs. For $1^{\text {st }}$ iteration & Abs. errs. For $2^{\text {nd }}$ iteration & Abs. errs. For $3^{\text {rditeration }}$ & Abs. errs. For $4^{\text {th }}$ iteration \\
\hline \multirow[t]{6}{*}{$t=0.1$} & $\mathbf{0}$ & 0.00000600124999983187 & $7.742699323627617 \times 10^{-7}$ & $1.320252550675336 \times 10^{-8}$ & $1.67004493323643 \times 10^{-9}$ \\
\hline & 0.2 & 0.000006033249999831014 & $8.539948308988224 \times 10^{-7}$ & $1.406757778557003 \times 10^{-8}$ & $1.837622725104753 \times 10^{-9}$ \\
\hline & 0.4 & 0.000006257249999825021 & $9.320281606034605 \times 10^{-7}$ & $1.530290758255603 \times 10^{-8}$ & $2.05549086807278 \times 10^{-9}$ \\
\hline & 0.6 & 0.000006865249999808754 & 0.000001006328729380217 & $1.746112293136207 \times 10^{-8}$ & $2.314295728200713 \times 10^{-9}$ \\
\hline & 0.8 & 0.000008049249999777076 & 0.000001073714315230005 & $2.128396463294381 \times 10^{-8}$ & $2.597436775633328 \times 10^{-9}$ \\
\hline & 1 & 0.000010 & 45093286537 & $2.767829010265537 \times 10^{-8}$ & $2.872778668825741 \times 10^{-9}$ \\
\hline \multirow[t]{7}{*}{$t=0.01$} & $\overline{x_{i}}$ & Abs. errs. For $1^{\text {st }}$ iteration & Abs. errs. For $2^{\text {nd }}$ iteration & Abs. errs. For $3^{\text {rditeration }}$ & Abs. errs. For $4^{\text {th }}$ iteration \\
\hline & $\mathbf{0}$ & $6.000000496442226 \times 10^{-11}$ & $7.97649253302486 \times 10^{-13}$ & $9.38428773337254 \times 10^{-17}$ & 1.070649645329 \\
\hline & 0.2 & $6.032000499089918 \times 10^{-11}$ & $8.77622012661146 \times 10^{-13}$ & $1.023660726055963 \times 10^{-16}$ & $1.233279971202261 \times 10^{-18}$ \\
\hline & 0.4 & $6.256000517623761 \times 10^{-11}$ & $9.574272321717656 \times 10^{-13}$ & $1.138474363261675 \times 10^{-16}$ & $1.45012040569936 \times 10^{-18}$ \\
\hline & 0.6 & $6.864000567929908 \times 10^{-11}$ & $1.036862409700589 \times 10^{-12}$ & $1.331019827670317 \times 10^{-16}$ & $1.707618421664664 \times 10^{-18}$ \\
\hline & 0.8 & $8.048000665894506 \times 10^{-11}$ & $1.115610940256718 \times 10^{-12}$ & $1.669606053641445 \times 10^{-16}$ & $2.087089182034583 \times 10^{-18}$ \\
\hline & 1 & $1.000000082740371 \times 10^{-10}$ & $1.193110458849249 \times 10^{-12}$ & $2.242460647913282 \times 10^{-16}$ & $2.493664996716629 \times 10^{-18}$ \\
\hline \multirow[t]{7}{*}{$t=0.001$} & $\overline{x_{i}}$ & Abs. errs. For $1^{\text {st }}$ iteration & Abs. errs. For $2^{\text {nd }}$ iteration & Abs. errs. For $3^{\text {rd }}$ iteration & Abs. errs. For $4^{\text {th }}$ iteration \\
\hline & $\mathbf{0}$ & $10^{-16}$ & $3.998857142857143 \times 10^{-19}$ & $9.392000002026451 \times 10^{-25}$ & 1.48331235938 \\
\hline & 0.2 & $6.696865284538944 \times$ & $4.798838784 \times 10^{-19}$ & $1.024444335758498 \times 10^{-24}$ & $2.117582368135751 \times 10^{-22}$ \\
\hline & 0.4 & $6.94555524205498 \times 10^{-16}$ & $5.598706176 \times 10^{-19}$ & $1.139348554054155 \times 10^{-24}$ & $2.117582368135751 \times 10^{-22}$ \\
\hline & 0.6 & $7.620570841027075 \times 10^{-16}$ & $6.398310107428573 \times 10^{-19}$ & $1.332174526510562 \times 10^{-24}$ & $2.117582368135751 \times 10^{-22}$ \\
\hline & 0.8 & $8.93507490218326 \times 10^{-16}$ & $7.197387264 \times 10^{-19}$ & $1.67146743228809 \times 10^{-24}$ & $2.117582368135751 \times 10^{-22}$ \\
\hline & 1 & $1.110223024625156 \times 10^{-15}$ & $7.995428571428572 \times 10^{-19}$ & $2.246031746364245 \times 10^{-24}$ & $3.004975599994815 \times 10^{-47}$ \\
\hline
\end{tabular}




\section{CONCLUSION}

In this paper, we presented and applied three iterative methods to solve the nonlinear 1D, 2D and 3D Fisher's equation. These methods can be applied without restriction conditions for nonlinear equations unlike VIM and ADM; where they required furthermore calculations like Adomian polynomials to handle the nonlinear terms in the ADM and calculate Lagrange multiplier as in the VIM which required additional time during the calculation process. It can be concluded, that the absolute error values and the maximum error remainder decreased when increased the iterations and decreased the time. Also, it has been noticed after solving 1D, 2D and 3D problems the TAM provided highest accuracy and required less time in comparison to the DJM and BCM. Moreover, the proposed methods: DJM, TAM, and BCM are accurate, reliable and applicable to solve the nonlinear problems. However, the limitation of the proposed methods that by increasing the interval of $x$ and $t$, the accuracy deteriorates and the error is increasing. Since these approaches lead to an expansion of the solution, where we increase the interval of $x$ and $t$, in fact we go farther from the initial point. Thus, the accuracy of the proposed methods diminishes as in Taylor exapansion.

\section{REFERENCES}

[1] Akyildiz FT, Siginer DA, Vajravelu K, Van Gorder RA. (2010) Analytical and numerical results for the Swift-Hohenberg equation. Applied Mathematics and Computation, 216(1):221-226.

[2] Al-Jawary MA. (2017) A semi-analytical iterative method for solving nonlinear thin film flow problems. Chaos, Solitons \& Fractals, 99:52-56.

[3] Al-Jawary MA, Azeez MM, Radhi GH. (2018) Analytical and numerical solutions for the nonlinear Burgers and advection-diffusion equations by using a semi-analytical iterative method. Computers \& Mathematics with Applications, 76(1):155-171.

[4] Sahib AAA, Hasan SQ. (2014) Convergence of the Generalized Homotopy Perturbation Method for Solving Fractional Order Integro-Differential Equations. Baghdad Science Journal, 11(4):1637-1648.

[5] Al-Hawasy JAA, Al-Rawdanee EH. (2019) Numerical Solution for Classical Optimal Control Problem Governing by Hyperbolic Partial Differential Equation via Galerkin Finite ElementImplicit method with Gradient Projection Method. Ibn AL-Haitham Journal For Pure and Applied Science, 32(2):71-80.

[6] Gorial II. (2011) Finite Difference Method for Two-Dimensional Fractional Partial Differential Equation with parameter. Ibn AL-Haitham Journal For Pure and Applied Science, 24(2).

[7] Mittal RC, Arora G. (2010) Efficient numerical solution of Fisher's equation by using Bspline method. International Journal of Computer Mathematics, 87(13):3039-3051.

[8] Matinfar M, Ghanbari M. (2009) The application of the modified variational iteration method on the generalized Fisher's equation. Journal of Applied Mathematics and Computing, 31(12):165-175.

[9] Verma A, Jiwari R, Koksal ME. (2014) Analytic and numerical solutions of nonlinear diffusion equations via symmetry reductions. Advances in Difference Equations, 2014(1):229.

[10] Tyson JJ, Brazhnik PK. (2000) On traveling wave solutions of Fisher's equation in two spatial dimensions. SIAM Journal on Applied Mathematics, 60(2):371-391. 
[11] Roessler J, Hüssner H. (1997) Numerical solution of the 1+ 2 dimensional Fisher's equation by finite elements and the Galerkin method. Mathematical and Computer Modelling, 25(3):57-67.

[12] Ağırseven D, Öziş T. (2010) An analytical study for Fisher type equations by using homotopy perturbation method. Computers \& Mathematics with Applications, 60(3):602-609.

[13] Rehman YU, Yaqub M, Ul-Hassan QM, Ayub K, Siddiqa A. (2017) Solving Fisher's Equation by Using Modified Variational Iteration Method. American Journal of Engineering, Technology and Society, 4(5):74.

[14] Al-Khaled K. (2001) Numerical study of Fisher's reaction-diffusion equation by the Sinc collocation method. Journal of Computational and Applied Mathematics, 137(2):245-255.

[15] Wazwaz AM, Gorguis A. (2004) An analytic study of Fisher's equation by using Adomian decomposition method. Applied Mathematics and Computation, 154(3):609-620.

[16] Parand K, Nikarya M. (2017) A numerical method to solve the 1D and the 2D reaction diffusion equation based on Bessel functions and Jacobian free Newton-Krylov subspace methods. The European Physical Journal Plus, 132(11):496.

[17] Daftardar-Gejji V, Jafari H. (2006) An iterative method for solving nonlinear functional equations. Journal of Mathematical Analysis and Applications, 316(2):753-763.

[18] Temimi H, Ansari AR. (2011) A semi-analytical iterative technique for solving nonlinear problems. Computers \& Mathematics with Applications, 61(2):203-210.

[19] Daftardar-Gejji V, Bhalekar S. (2009) Solving nonlinear functional equation using Banach contraction principle. Far East Journal of Applied Mathematics, 34(3):303-314.

[20] Al-Jawary MA, Adwan MI, Radhi GH. (2018) Three iterative methods for solving second order nonlinear ODEs arising in physics. Journal of King Saud University-Science, 23(1):312-323.

[21] AL-Jawary MA, Radhi GH, Ravnik J. (2018) Daftardar-Jafari method for solving nonlinear thin film flow problem. Arab Journal of Basic and Applied Sciences, 25(1):20-27.

[22] Al-Jawary MA, Raham RK. (2017) A semi-analytical iterative technique for solving chemistry problems. Journal of King Saud University-Science, 29(3):320-332.

[23] Al-Jawary MA, Radhi GH, Ravnik J. (2017) Semi-analytical method for solving FokkerPlanck's equations. Journal of the Association of Arab Universities for Basic and Applied Sciences, 24:254-262.

[24] AL-Jawary MA. (2016) An efficient iterative method for solving the Fokker-Planck equation. Results in Physics, 6:985-991.

[25] Abdul Nabi AJ, AL-Jawary MA. (2018) Analytical and Numerical Solutions for the Linear and Nonlinear 1D, 2D and 3D Telegraph Equations. Journal of Advanced Research in Dynamical and Control Systems, 10(10-Special):2090-2105.

[26] Mitlif RJ. (2014) New Iterative Method for Solving Nonlinear Equations. Baghdad Science Journal, 11(4):1649-1654.

[27] Daftardar-Gejji V, Bhalekar S. (2010) Solving fractional boundary value problems with Dirichlet boundary conditions using a new iterative method. Computers \& Mathematics with Applications, 59(5):1801-1809.

[28] Temimi H, Ansari AR. (2011) A new iterative technique for solving nonlinear second order multi-point boundary value problems. Applied Mathematics and Computation, 218(4):14571466.

[29] Odibat ZM. (2010) A study on the convergence of variational iteration method. Mathematical and Computer Modelling, 51(9-10):1181-1192. 
[30] Mittal RC, Kumar S. (2006) Numerical study of Fisher's equation by wavelet Galerkin method. International Journal of Computer Mathematics, 83(3):287-298.

[31] Mavoungou T, Cherruault Y. (1994) Numerical study of Fisher's equation by Adomian's method. Mathematical and computer modelling, 19(1):89-95. 